\title{
Poly(hexamethylene terephthalate-co-caprolactone) copolymers: Influence of cycle size on ring-opening polymerization
}

\author{
Nathalie González-Vidal, Antxon Martínez de Ilarduya, Sebastián Muñoz-Guerra. \\ Departament d'Enginyeria Química, Universitat Politècnica de Catalunya, \\ ETSEIB, Diagonal 647, 08028 Barcelona, Spain
}

\begin{abstract}
Poly(hexamethylene terephthalate) was cyclo-depolymerized in solution by heating to yield a fraction of cyclic oligomers of hexamethylene terephthalate $\left(c(\mathrm{HT})_{2-5}\right)$ with a content around to $95 \%$ in dimer to pentamer. Ring-opening polymerization in the melt of $c(\mathrm{HT})_{2-5}$, either neat or in mixtures with $\varepsilon$-caprolactone $(C L)$ covering a range of $H T / C L$ ratios from 9/1 to 1/9 was carried out to produce polyesters with molecular weights above 30,000 in high yields. The copolyesters had a comonomer composition according to the feed and the microstructure evolved from random to blocky as the content in $\mathrm{CL}$ increases. The thermal and mechanical properties of the copolyesters were evaluated for a variety of compositions. Results obtained in this work were compared to those previously obtained by us in the ring-opening copolymerization of CL with a cyclic oligomeric fraction enriched in hexamer and heptamer $\left(c(\mathrm{HT})_{6-7}\right)$. Although the polyesters resulting from the use of these two fractions were similar, significant differences were found in polymerization rate evidencing a lower reactivity of $c(\mathrm{HT})_{n}$ with decreasing values of $n$.
\end{abstract}

\footnotetext{
${ }^{*}$ Corresponding author: Tel. +34 934010910; Fax. +34 934017150

E-mail address: antxon.martinez.de.ilarduia@upc.edu (A. Martínez de llarduya)
} 


\section{Introduction}

Aromatic polyesters are typically prepared by step-growth polycondensation in the melt $[1,2]$. A second option is the ring-opening polymerization (ROP) of cyclic oligoesters under solvent free conditions [3]. This methodology is widely used in the synthesis of aliphatic polyesters as polyglycolide and polylactide, poly(E-caprolactone) or poly(p-dioxanone) [4-6]. In this method, the polyester is prepared from low-viscosity precursors by an entropically driven process that evolves without releasing of volatiles or emission of heat. However, the potential of ROP is strongly constrained by the limited availability of suitable cyclic monomers. Increasing attention is being paid recently to the utilization of cyclic oligoesters as feedstock for the synthesis and processing of aromatic polyesters [3, 7-9]. One source of cyclic oligoesters of great interest is cyclo-depolymerization of linear polyesters, which in combination with ROP, would provide an environmentally friendly route for the chemical recycling of currently important thermoplastics as poly(ethylene terephthalate) (PET), poly(butylene terephthalate) (PBT) and other closely related industrial aromatic polyesters and copolyesters [10-14].

Poly(hexamethylene terephthalate) (PHT) is a semi-crystalline aromatic polyester that has not been industrially used to date. The presence of the hexamethylene segment confers to this polyester a great chain flexibility that is reflected in a relatively low $T_{\mathrm{g}}\left(\sim 10^{\circ} \mathrm{C}\right)$ and a moderate $T_{\mathrm{m}}\left(\sim 140{ }^{\circ} \mathrm{C}\right)$ as compared to PET [15-16]. Nevertheless, PHT continues exhibiting good mechanical properties and chemical resistance characteristic of aromatic polyesters [17]. PHT is not biodegradable, and as it happens with other poly(phthalate)s, block copolyesters of hexamethylene terephthalate $(\mathrm{HT})$ and $\varepsilon$-caprolactone have been explored for their potential as biodegradable materials for packaging [18]. Recently we succeeded in preparing copolyesters of $\mathrm{HT}$ and $\varepsilon$-caprolactone (CL) by ROP. A fraction of hexamethylene terephthalate cyclic oligomers consisting of a mixture of hexamer and heptamer $c(\mathrm{HT})_{6-7}$ prepared by cyclo-depolymerization of PHT was used for this synthesis [19].

In this paper we wish to report again on the preparation of poly(hexamethylene terephthalate-cocaprolactone) copolyesters by ROP, but now using a fraction of cyclic hexamethylene terephthalate oligomers $c(\mathrm{HT})_{2-5}$ enriched in dimmer to pentamer. The aim of the work is to evaluate the influence of the size of the cyclic oligoesters on the ring-opening polymerization 
reaction and on the structure and properties of the resulting polyesters. Firstly the oligomeric $c(\mathrm{HT})_{2-5}$ fraction was prepared by cyclo-depolymerization of PHT and characterized in full detail. Secondly, a series of copolyesters with a ratio of HT to CL ranging from 90/10 to 10/90, in addition to the PHT homopolymer, were prepared by ROP. The progress of the polymerization reaction using one or the other fraction, as well as the chemical structure and thermal properties of the copolyesters generated in each case were comparatively studied.

\section{Experimental}

\subsection{Materials and measurements}

Dimethyl terephthalate (DMT) (99\%), hexanediol (HD) (99\%), $\varepsilon$-caprolactone (CL) $(>99 \%)$, dibutyltin oxide (DBTO) (98\%), tin octanoate (Sn(Oct) $)_{2}$ (95\%), and 1,2-dichlorobenzene (DCB) (99\%) were purchased from Sigma-Aldrich Co. and were used without further purification. Antimony (III) oxide (97\%, Panreac Co) was reagent grade and used as received. The solvents used for purification and characterization, such as methanol, chloroform, dichloromethane (DCM), tetrahydrofuran (THF), diethyl ether, dichloroacetic acid (DCA), and 1,1,1,3,3,3hexafluoro-2-propanol (HFIP), were high-purity grade and used as received.

${ }^{1} \mathrm{H}$ and ${ }^{13} \mathrm{C}$ NMR spectra were recorded at $25.0{ }^{\circ} \mathrm{C}$ on a Bruker $\mathrm{AMX}-300$ spectrometer operating at 300.1 and $75.5 \mathrm{MHz}$, respectively. Both polyesters and cyclic compounds were dissolved in deuterated chloroform or a mixture of deuterated chloroform/trifluoroacetic acid (9/1), and spectra were internally referenced to tetramethylsilane. About 10 and $50 \mathrm{mg}$ of sample in $1 \mathrm{~mL}$ of solvent were used for ${ }^{1} \mathrm{H}$ and ${ }^{13} \mathrm{C}$, respectively. Sixty-four scans were recorded for ${ }^{1} \mathrm{H}$, and between 1000 and 10000 scans for ${ }^{13} \mathrm{C} \mathrm{NMR}$, with 32 and $64 \mathrm{~K}$ data points and relaxation delays of 1 and $2 \mathrm{~s}$, respectively. Matrix-assisted laser desorption/ionization time-of-flight (MALDI-TOF) mass spectra were recorded in a 4700 Proteomics Analyzer instrument (Applied Biosystems). Spectra acquisition was performed in the MS reflector positive ion mode. About 0.1 mg of sample was dissolved in $50 \mu \mathrm{L}$ of DCM and $2 \mu \mathrm{L}$ of this solution were mixed with an equal volume of DCM solution of anthracene $\left(10 \mathrm{mg} \cdot \mathrm{mL}^{-1}\right)$ and the mixture left to evaporate to dryness onto the stainless steel plate of the analyzer. The residue was then covered with $2 \mu \mathrm{L}$ of a solution of 2,5-dihydroxibenzoic acid in acetonitrile/ $\mathrm{H}_{2} \mathrm{O}(1 / 1)$ containing $0.1 \%$ TFA and the mixture was left to dry prior to exposition to the laser beam. 
High performance liquid chromatography (HPLC) analysis were carried out at $25.0{ }^{\circ} \mathrm{C}$ in a Waters apparatus equipped with a UV detector of Applied Biosystems operating at $254 \mathrm{~nm}$ wavelength, and a Scharlau Science column (Si60, $5 \mu \mathrm{m} ; 250 \times 4.6 \mathrm{~mm}$ ). Cyclic oligomers (1 $\mathrm{mg}$ ) were dissolved in chloroform $(1 \mathrm{~mL})$ and eluted with hexane/1,4-dioxane $(70 / 30 \mathrm{v} / \mathrm{v})$ at a flow rate of $1.0 \mathrm{~mL} \cdot \mathrm{min}^{-1}$. Molecular weight analysis were performed by GPC using HFIP containing sodium trifluoroacetate $\left(6.8 \mathrm{~g} \cdot \mathrm{L}^{-1}\right)$ in a Waters equipment provided with RI and UV detectors. $100 \mu \mathrm{L}$ of $0.1 \%(\mathrm{w} / \mathrm{v})$ sample solution were injected and chromatographed with a flow of $0.5 \mathrm{~mL} \cdot \mathrm{min}^{-1}$. HR5E and HR2 Waters linear Styragel columns $(7.8 \mathrm{~mm} \times 300 \mathrm{~mm}$, pore size $10^{3}-10^{4} \AA$ ) packed with crosslinked polystyrene and protected with a precolumn (VanGuard, 1.8 $\mu \mathrm{m}, 2.1 \times 5 \mathrm{~mm}$ ) were used. Molecular weight averages and distributions were evaluated against PMMA standards. Intrinsic viscosities were measured from polymer solutions in DCA using an Ubbelohde viscometer thermostatted at $25.0 \pm 0.1^{\circ} \mathrm{C}$.

The thermal behavior of cyclic compounds and polymers was examined by differential scanning calorimetry (DSC), using a Perkin-Elmer Pyris 1 apparatus. Thermograms were obtained from 4$6 \mathrm{mg}$ samples at heating and cooling rates of $10^{\circ} \mathrm{C} \cdot \mathrm{min}^{-1}$ under a nitrogen flow of $20 \mathrm{~mL} \cdot \mathrm{min}^{-1}$. Indium and zinc were used as standards for temperature and enthalpy calibration, respectively. The glass transition temperature $\left(T_{\mathrm{g}}\right)$ was taken as the inflection point of the heating DSC traces recorded at $20^{\circ} \mathrm{C} \cdot \mathrm{min}^{-1}$ from melt-quenched samples, and melting temperature $\left(T_{\mathrm{m}}\right)$ was taken as the maximum of the endothermic peak appearing on heating traces. The tensile tests were conducted at room temperature on a Zwick BZ2.5/TN1S universal tensile testing apparatus operating at a constant crosshead speed of $10 \mathrm{~mm} \cdot \mathrm{min}^{-1}$ using a $0.5-\mathrm{N}$ preload and a grip-to-grip separation of $20 \mathrm{~mm}$. All reported tensile data represent an average of at least six independent measurements. Mechanical testing was performed on melt compression samples $4 \mathrm{~mm}$ width with an average thickness of $0.16 \mathrm{~mm}$.

\subsection{Synthesis of cyclic oligomers $c(H T)_{n}$ by cyclo-depolymerization of PHT.}

PHT was synthesized to be used as the source for cyclic oligomers of hexamethylene terephthalate. It was prepared by conventional polycondensation of HD and DMT according to a procedure described by us [19], which was a modification of a procedure previously described in the literature [15]. The PHT was obtained in $84 \%$ yield with a weight-average molecular weight of 63,000, a $T_{\mathrm{g}} \sim 10{ }^{\circ} \mathrm{C}$ and a $T_{\mathrm{m}} \sim 140{ }^{\circ} \mathrm{C}$. NMR $\left(\mathrm{CDCl}_{3}, 300 \mathrm{MHz}\right): \delta$ (ppm) 8.09 (s, 4H, ArH), 
$4.36\left(\mathrm{t}, 4 \mathrm{H}, \mathrm{OCH}_{2}\right), 1.83$ (q, $\left.4 \mathrm{H}, \mathrm{OCH}_{2} \mathrm{CH}_{2}\right), 1.56\left(\mathrm{~m}, 4 \mathrm{H}, \mathrm{OCH}_{2} \mathrm{CH}_{2} \mathrm{CH}_{2}\right) .{ }^{13} \mathrm{C}\left\{{ }^{1} \mathrm{H}\right\}-\mathrm{NMR}\left(\mathrm{CDCl}_{3}\right.$, $75.5 \mathrm{MHz})$ : $\delta$ (ppm) $165.8(\mathrm{C}=\mathrm{O}), 134.1,129.5(\mathrm{ArC}), 65.3\left(\mathrm{OCH}_{2}\right), 28,6\left(\mathrm{OCH}_{2} \mathrm{CH}_{2}\right), 25.7$ $\left(\mathrm{OCH}_{2} \mathrm{CH}_{2} \mathrm{CH}_{2}\right)$.

Cyclic oligomers were produced by cyclo-depolymerization of PHT according to the following procedure: PHT (4.96 g, $20 \mathrm{mmol}$ previously dried overnight in a vacuum oven at $60{ }^{\circ} \mathrm{C}$ ) and DCB $(200 \mathrm{~mL})$ containing $3 \%$-mole of DBTO were introduced into a $250 \mathrm{~mL}$ round-bottom flask equipped with a condenser. This mixture was stirred vigorously, and the reaction was allowed to proceed under refluxing at a temperature of $180{ }^{\circ} \mathrm{C}$ for a period of time between 2 and 8 days, cooled to room temperature and filtered. The clear solution was rapidly evaporated under vacuum at $50{ }^{\circ} \mathrm{C}$ to dryness, and the recovered solid was washed in methanol and dried at 50 ${ }^{\circ} \mathrm{C}$ under reduced pressure for $48 \mathrm{~h}$ before characterization. The recovered solid $(4.2 \mathrm{~g}, 85 \%$ yield), consisted of a mixture of cyclic oligomers containing near $90 \%$ of dimer to pentamer, considering the dimer, trimer, tetramer, etc, as composed of two, three or four hexamethylene terephthalate units respectively. ${ }^{1} \mathrm{H} \mathrm{NMR}\left(\mathrm{CDCl}_{3}, 300 \mathrm{MHz}\right): \delta(\mathrm{ppm})$ 8.08-8.06 $(3 \mathrm{~s}, 2.6 \mathrm{H}, \mathrm{ArH})$, $7.87\left(\mathrm{~s}, 1.4 \mathrm{H}\right.$, ArH dimer), $4.41\left(\mathrm{~m}, 4 \mathrm{H}, \mathrm{OCH}_{2}\right), 1.84\left(\mathrm{~m}, 4 \mathrm{H}, \mathrm{OCH}_{2} \mathrm{CH}_{2}\right), 1.63(\mathrm{~m}, 1.4 \mathrm{H}$, $\mathrm{OCH}_{2} \mathrm{CH}_{2} \mathrm{CH}_{2}$ dimer), $1.54\left(\mathrm{~m}, 2.6 \mathrm{H}, \mathrm{OCH}_{2} \mathrm{CH}_{2} \mathrm{CH}_{2}\right) \cdot{ }^{13} \mathrm{C}\left\{{ }^{1} \mathrm{H}\right\}-\mathrm{NMR}\left(\mathrm{CDCl}_{3}, 75.5 \mathrm{MHz}\right): \delta(\mathrm{ppm})$ $165.8(\mathrm{C}=\mathrm{O}), 165.6$ ( $\mathrm{C}=\mathrm{O}$ dimer), 134.1, $129.5(\mathrm{ArC}), 133.8,129.3$ (ArC dimer), $65.3\left(\mathrm{OCH}_{2}\right.$ dimer), 65,2 $\left(\mathrm{OCH}_{2}\right), 28,5\left(\mathrm{OCH}_{2} \mathrm{CH}_{2}\right), 28.3\left(\mathrm{OCH}_{2} \mathrm{CH}_{2}\right.$ dimer $), 25.8\left(\mathrm{OCH}_{2} \mathrm{CH}_{2} \mathrm{CH}_{2} \operatorname{dimer}\right), 25.7$ $\left(\mathrm{OCH}_{2} \mathrm{CH}_{2} \mathrm{CH}_{2}\right)$.

\subsection{Synthesis of PHT by ring-opening polymerization of $c(H T)_{n}$.}

$c(\mathrm{HT})_{2-5}(0.2 \mathrm{~g}, 0.8 \mathrm{mmol})$ and $\mathrm{Sb}_{2} \mathrm{O}_{3}$ catalyst $(1.17 \mathrm{mg}, 0.5 \%$-mole) were introduced into a vial and mixed by dissolving them in DCM and then the solvent slowly evaporated under vigorous stirring. The residue was dried at $50{ }^{\circ} \mathrm{C}$ under reduced pressure for $24 \mathrm{~h}$. The dried mixture was introduced into a two-necked round-bottom flask equipped with a nitrogen inlet/outlet. The flask was purged with nitrogen to remove all traces of moisture and residual air and immersed into an oil bath at either $175^{\circ} \mathrm{C}$ or $200{ }^{\circ} \mathrm{C}$ and polymerization was carried out for 120 min under a nitrogen atmosphere. The reaction mixture was quenched in an ice-water bath and the atmospheric pressure was recovered using nitrogen to prevent degradation. The resulting polymer was dissolved in chloroform and precipitated with cold methanol. $\left(0.18 \mathrm{~g}, 92 \%\right.$ yield). ${ }^{1} \mathrm{H}$ $\operatorname{NMR}\left(\mathrm{CDCl}_{3}, 300 \mathrm{MHz}\right): \delta(\mathrm{ppm}) 8.08(\mathrm{~s}, 4 \mathrm{H}, \mathrm{ArH}), 4.36\left(\mathrm{t}, 4 \mathrm{H}, \mathrm{OCH}_{2}\right), 1.83\left(\mathrm{~m}, 4 \mathrm{H}, \mathrm{OCH}_{2} \mathrm{CH}_{2}\right)$, 
$1.54\left(\mathrm{~m}, 4 \mathrm{H}, \mathrm{OCH}_{2} \mathrm{CH}_{2} \mathrm{CH}_{2}\right) \cdot{ }^{13} \mathrm{C}\left\{{ }^{1} \mathrm{H}\right\}-\mathrm{NMR}\left(\mathrm{CDCl}_{3}, 75.5 \mathrm{MHz}\right): \delta(\mathrm{ppm}) 165.8(\mathrm{C}=\mathrm{O}), 134.1$, $129.5(\mathrm{ArC}), 65,3\left(\mathrm{OCH}_{2}\right), 28,6\left(\mathrm{OCH}_{2} \mathrm{CH}_{2}\right), 25.7\left(\mathrm{OCH}_{2} \mathrm{CH}_{2} \mathrm{CH}_{2}\right)$.

2.4. Synthesis of poly(hexamethylene terephthalate-co-caprolactone) copolyesters $\left(P H T_{x} C L_{y}\right)$ by ring-opening polymerization.

A mixture of cyclic oligomers $c(\mathrm{HT})_{2-5}$ and $\mathrm{CL}$ with the selected composition ratio and $\mathrm{Sb}_{2} \mathrm{O}_{3}(0.5$ $\%$-mole), was introduced into a two-necked round-bottom flask equipped with a nitrogen inlet/outlet. The flask was purged with nitrogen to remove all traces of moisture and residual air, and immersed in an oil heating bath. The reaction was carried out at $175^{\circ} \mathrm{C}$ for 120 min under a circulating nitrogen atmosphere. The final reaction mixture was quenched in an ice-water bath, and the atmospheric pressure was recovered using nitrogen to prevent degradation. The resulting copolymers were dissolved in chloroform and precipitated with cold methanol and obtained in over $99 \%$ yield.

\section{Results and discussion}

\subsection{Synthesis and characterization of $c(H T)_{2-5}$ by cyclo-depolymerization of PHT}

The PHT used as raw material for the production of the $c(\mathrm{HT})_{2-5}$ cyclic oligomers was synthesized by polycondensation of HD and DMT with a weight-average molecular weight of 63,000 and a polydispersity near to 2 . Scheme 1 shows the cyclo-depolymerization reaction and includes the synthesis of $\mathrm{PHT}$ via ring opening polymerization from $c(\mathrm{HT})_{2-5}$ cyclic oligomers and poly(hexamethylene terephthalate-co-caprolactone) copolyesters $\left(\mathrm{COPHT}_{x} \mathrm{CL}_{y}\right)$ in the bulk from cyclic hexamethylene terephthalate oligomers and $\varepsilon$-caprolactone using $\mathrm{Sb}_{2} \mathrm{O}_{3}$ as catalyst.

Following our own experience in the preparation of $c(\mathrm{HT})_{\mathrm{n}}$ from $\mathrm{PHT}$ [19], cyclodepolymerization reactions were carried out in refluxing DCB and using DBTO as catalyst. Different reaction times and dilutions were tried in order to optimize the formation of cyclic oligomers. Results obtained along this experimentation are compared in Table 1. Best yields were achieved for longer periods of reaction time and using highly dilute concentrations. Conversely no significant alteration in the distribution of cycle sizes took place upon changing such variables. This distribution of cycle sizes was in all cases close to that reported by Brunelle 
et al. [7] for a cyclic fraction prepared by reaction of terephthaloyl chloride with hexamethylene glycol in solution at high dilution conditions. Such fraction consisted of species ranging from the dimer to the heptamer with percentage contents decreasing with the increase of cycle size. This weigh distribution of cyclics was calculated considering that all cyclic oligomers have the same detector response per unit weight, a fact that can be assumed if the cycles considered have the same repeating units, then the same cromophores. The fraction obtained at PHT concentration of $0.06 \mathrm{~mol} \cdot \mathrm{L}^{-1}$ after 4 days of reaction was used for ROP in this work.

The procedure applied for the characterization of the cyclic products obtained by cyclodepolymerization of PHT deserves some comments. Firstly the ${ }^{1} \mathrm{H}$ NMR analysis was used to assess the chemical constitution as well as to check the absence of linear oligomers whose occurrence would be evidenced by the presence of signals arising from both hydroxymethyl and aromatic acid end-groups at around $3.6 \mathrm{ppm}$ and 8.1-8.2 ppm respectively. The HPLC chromatograms of the crude fraction displayed six well separated peaks corresponding to monodisperse oligomers from dimer to heptamer (Figure 1a). Assignment of these peaks was made by MALDI-TOF analysis after their isolation by semi-preparative HPLC (Figure 1b). It was found that each hexamethylene terephthalate cyclic oligomer of $\mathrm{M}$ mass was accompanied by a minor amount of the $M+100$ compound, which was identified by NMR as the corresponding oligomer with one hexamethylene glycol unit replaced by one di(hexamethylene glycol) unit. As it can be expected, these di(hexamethylene glycol) containing oligomers were not reported to be present in the cyclic fractions produced by chemical synthesis from diadic chlorides and diols due to milder conditions used for the synthesis [7].

\subsection{Synthesis of PHT by ring-opening polymerization of $c(H T)_{n}$}

The ring-opening polymerization of the cyclic oligomers $c(\mathrm{HT})_{2-5}$ was carried out at $175^{\circ} \mathrm{C}$ or 200 ${ }^{\circ} \mathrm{C}$ for 120 min either in the presence of $0.5 \%$-mole of catalyst $\left(\mathrm{Sb}_{2} \mathrm{O}_{3}\right.$, DBTO or $\left.\mathrm{Sn}(\mathrm{Oct})_{2}\right)$ or without catalyst. The intrinsic viscosities of the resulting polymers are listed in Table 2 and data available for fraction $c(\mathrm{HT})_{6-7}$ [19] were included for comparison. The viscosity of the cyclic oligomers was $0.09 \mathrm{dL} \cdot \mathrm{g}^{-1}$ and it increased significantly upon heating indicating that the ring opening polymerization reaction proceeded. As expected, larger increases in viscosity were attained at higher temperatures. Although the highest viscosity values were achieved with $\mathrm{Sb}_{2} \mathrm{O}_{3}$ and $\mathrm{Sn}(\mathrm{Oct})_{2}$, polymerization was observed to proceed even in the absence of catalyst upon 
heating at $200{ }^{\circ} \mathrm{C}$. In this case, it should be assumed that reaction was activated by catalyst residues used in the cyclo-depolymerization reaction, which were not removed by the used purification procedure.

The evolution of polymer size and dimer content with polymerization time was followed by viscosimetry and ${ }^{1} \mathrm{H}$ NMR respectively, and results are shown in Figure 2 . As expected, the intrinsic viscosity increased to attain values between 0.5 and $0.6 \mathrm{dL} \cdot \mathrm{g}^{-1}$ to become nearly asymptotic after $3 \mathrm{~h}$ of reaction (Figure $2 \mathrm{a}$ ). The ${ }^{1} \mathrm{H}$ NMR analysis of the reaction mixture revealed the intake of $c(\mathrm{HT})_{2}$ and $c(\mathrm{HT})_{3}$ with reaction time (Figure $2 \mathrm{~b}$ ) as the disappearance of the signal at $7.89 \mathrm{ppm}$ and $8.08 \mathrm{ppm}$, respectively. dimer and trimer NMR peaks were assigned in base of the NMR aromatic proton areas and HPLC data, showing a good correlation with the content in both cycles by the two techniques. After $15 \mathrm{~min}$ of reaction, $65 \%$ and $75 \%$ of the initial dimer and trimer amounts remained unreacted, and after $30 \mathrm{~min}$ of reaction, the left amounts were $30 \%$ and $16 \%$, respectively. The signal of the trimer completely disappeared after 60 min of reaction, whereas small amounts of dimer were still present at the end of the reaction. These results evidenced the reluctance of the cyclic dimer to polymerize compared to the trimer. Unfortunately this analysis was not feasible with cycles of larger sizes since in such cases no NMR signal discriminating between open and close chains could be detected.

The reactivity of $c(\mathrm{HT})_{2-5}$ and $c(\mathrm{HT})_{6-7}$ in ROP were then compared. The evolution of intrinsic viscosity with reaction time is plotted in Figure $2 \mathrm{c}$ for each cyclic fraction. What is worthy to note is that a high viscosity was attained at very short reaction times in the ROP of $c(\mathrm{HT})_{6-7}$, and that such viscosity was superior to all other cases in which the $c(\mathrm{HT})_{2-5}$ fraction was used (Table 2), suggesting a higher reactivity of the $c(\mathrm{HT})_{6-7}$ cycles compared to $c(\mathrm{HT})_{2-5}$. The slower reactivity of smaller cycles, could be due to its lower ring strain, although conclusive results could be obtained using Molecular Orbital (MO) calculations. There are other related works on ring opening polymerization of cyclic sulfites [20] or lactones with PET [21] were the smaller cycles were observed to polymerize with difficulty or nor polymerize due to its very low ring strain.

The heating and cooling DSC traces of $c(\mathrm{HT})_{2-5}$ and $c(\mathrm{HT})_{6-7}$ fractions are shown in Figures 3a and $3 \mathrm{~b}$ respectively. In both cases, the first heating trace shows a broad endothermic peak attributed to the melting of the cycles. In the second heating, a narrower melting peak should be attributed to melting of the cycles as well as the small portion of oligomers or polymer which 
were produced in the first the thermal treatment due to the residual catalyst present in those samples. Apparently, the $c(\mathrm{HT})_{6-7}$ displayed higher melting temperature and enthalpy as should be expected for a cycle plus oligomer which have higher molecular weight.

The change in molecular weight of $c(\mathrm{HT})_{2-5}$ with reaction time is shown in Figure 3c. Both the weight-average and the number-average molecular weights were found to increase with time at different rates giving rise to an increase in polydispersity as the reaction proceeded. It is observed that after heating for $5 \mathrm{~min}$ at $200{ }^{\circ} \mathrm{C}$ some $c(\mathrm{HT})_{2-5}$ was converted to PHT. This is taken as a clear evidence that the thermal changes detected in the second heating DSC traces must arise from the melting of mixtures of cycles and the polymer formed from them in the first heating.

The results afforded a clear indication that smaller size $c(\mathrm{HT})_{\mathrm{n}}$ cycles display lower ROP reactivity, and are consistent with the relatively low reactivity displayed by $c(\mathrm{HT})_{2}$ in the polymerization of the $c(\mathrm{HT})_{2-5}$ fraction.

\subsection{Synthesis of $\operatorname{coPHT} T_{x} \mathrm{CL}_{y}$ copolymers by ring opening polymerization}

$c(\mathrm{HT})_{2-5}$ cyclic oligomers and $\mathrm{CL}$ were copolymerized applying the same method described previously by us for the preparation of $\mathrm{COPHT}_{x} \mathrm{CL}_{y}$ using the $c(\mathrm{HT})_{6-7}$ fraction [19]. Mixtures with $\mathrm{HT} / \mathrm{CL}$ molar ratios ranging between $10 / 90$ and $90 / 10$ were heated at $175^{\circ} \mathrm{C}$ in the presence of $\mathrm{Sb}_{2} \mathrm{O}_{3}$. Polymerization results and characteristics of the copolymers produced are given in Tables 3 and 4.

The evolution of the copolymerization reaction of the equimolar mixture of $c(\mathrm{HT})_{2-5}$ and $\mathrm{CL}$ was followed by GPC; the increasing in the $M_{w}$ with time is plotted in Figure 4 and compared with similar data recorded for the copolymerization of the $c(\mathrm{HT})_{6-7} / \mathrm{CL}$ mixtures with the same composition. The reactivity of larger size $c(\mathrm{HT})_{\mathrm{n}}$ cycles was brought again in evidence since the earlier reaction stages. Furthermore, the NMR analysis of the reaction mixture revealed the presence of an appreciable amount of dimer that was decreasing as the reaction progressed. The GPC chromatograms of the $\mathrm{COPHT}_{x} \mathrm{CL}_{y}$ copolyesters resulting after $120 \mathrm{~min}$ of reaction displayed a single peak characteristic of unimodal distribution. Weight-average molecular weights oscillating between 30,000 and 40,000 with polydispersities around 2 were obtained in the copolymerization of mixtures containing $c(\mathrm{HT})_{2-5}$. The $M_{w}$ of the copolyesters prepared from 
$c(\mathrm{HT})_{6-7}$ were notably higher for any $\mathrm{HT} / \mathrm{CL}$ ratio used but without significant differences in polydispersity.

The chemical structure and microstructure of the copolyesters were determined by ${ }^{1} \mathrm{H}$ and ${ }^{13} \mathrm{C}$ NMR analysis. The ${ }^{1} \mathrm{H}$ NMR spectra of 50/50 copolyester with full signal assignment is shown in Figure 5 for illustration. The $\mathrm{HT} / \mathrm{CL}$ contents were precisely determined from ${ }^{1} \mathrm{H}$ NMR spectra by integration of the $\varepsilon$-methylene protons of caprolactone (signal 5) and both $\alpha$-methylene protons of hexamethylene (signals a, a') and caprolactone (signals 1, 1') units. These results revealed that the composition used in the feed was essentially maintained in the respective resulting copolyester, and that it was so from the beginning of the copolymerization reaction. This behavior is similar to that observed in the copolymerization of $c(\mathrm{HT})_{6-7}$ and $\mathrm{CL}$ mixtures.

The microstructure of the copolyesters was analyzed for all the essayed compositions. As it can be seen in Fig. $6 a$, the ${ }^{13} \mathrm{C}$ NMR spectra appeared to be extremely sensitive to triad sequence effects. In fact, four peaks were observed in the region of the ${ }^{13} \mathrm{C}$ NMR spectra for each the $\alpha-$, $\beta-$, and $\gamma-\mathrm{CH}_{2}$ of hexamethylene $(\mathrm{H})$ as well as for the $\delta$ - and $\varepsilon-\mathrm{CH}_{2}$ caprolactone (CL) units. Taking the signals due to the $\beta$-methylene of $\mathrm{H}$ units, the quantification of the different peaks (b, b' ,b”, b"') applying Lorentzian deconvolution allowed to calculate the conditional probability $\left(P\left(A_{H} / B_{T}\right)=P\left(B_{T} / A_{H}\right)=a\right)$. With this value and following the methodology developed by Tessier et al. [22] for condensation copolymers containing both symmetrical and unsymmetrical units, the degree of randomness was calculated using the following expression:

$$
B=(1-a)\left(2 x_{T}+x_{C L}\right) / x_{C L}
$$

where $\mathrm{x}_{\mathrm{T}}$ and $\mathrm{x}_{\mathrm{CL}}$ are the molar ratio of terephthalate and caprolactone in the copolymer. As it can be seen in Table 3, the degree of randomness decreased with the content in CL from a value near to unity for the $\mathrm{coPHT}_{90} \mathrm{CL}_{10}$ to 0.5 for $\mathrm{coPHT}_{10} \mathrm{CL}_{90}$ indicating that the copolymers with a low content in $\mathrm{CL}$ were almost at random whereas for high content in these units displayed some block copolymer character. The calculated values are almost coincident with those calculated for the copolymers obtained in the copolymerization of $c(\mathrm{HT})_{6-7}$ and $C L$ mixtures using this methodology (Table 4) whose values show slight deviations to previously published ones [19] (see supplementary information). It is worthy to note that a decrease in the degree of 
randomness with the increasing content in lactone had been previously observed for copolyesters obtained in the high temperature reaction of poly(ethylene terephthalate) with lactones [21].

For the $\mathrm{coPHT}_{50} \mathrm{CL}_{50}$ copolyester, a detailed study of the progress of the reaction as a function of time was carried out. The evolution of copolymer microstructure with reaction time was monitored via the changes observed for the ${ }^{13} \mathrm{C}$ NMR signals arising from the $\beta-\mathrm{CH}_{2}$ of the hexamethylene as well as the signals due to $\delta$-, and $\varepsilon-\mathrm{CH}_{2}$ of the $\mathrm{CL}$ units, which are known to be well resolved at the level of triads. As it can be observed in Figure 6b, the signals due to homosequences decreased and new peaks due to heterosequences increased as the reaction proceeded. A detailed account of the NMR analysis results is provided in Table 4, where experimental copolyester compositions, the contents in $\mathrm{H}$-unit centered triads and the degree of randomness are given for increasing reaction times. These results reveal that a block microstructure was generated a short reaction times, which evolved to a nearly random distribution as the reaction proceeded. Similar results were observed for some copolymers obtained wich were obtained by entropically driven ring-opening polymerization using macrocyclic oligoesters [23]. The evolution of randomness with reaction time of the copolymer $50 / 50$ synthesized from $c(\mathrm{HT})_{2-5}$ is plotted in Figure 7 and compared with similar data recorded for the copolymerization of the $c(\mathrm{HT})_{6-7} / \mathrm{CL}$ mixture with the same composition. At early reaction stages the copolyester made from $c(\mathrm{HT})_{2-5}$ cycles is more blocky than that prepared from $c(\mathrm{HT})_{6-}$ 7. It seems therefore that the relative reactivities of terephthalate and caprolactone cycles are closer for larger sizes of the formers. In both cases, after $90 \mathrm{~min}$ of reaction, the microstructure is mostly random due to extensive transesterification reactions taking place a high temperatures.

\subsection{Thermal and mechanical properties of $\operatorname{coPHT} T_{x} C L_{y}$.}

The thermal data of $\mathrm{COPHT}_{x} \mathrm{CL}_{y}$ copolyesters obtained by ROP of mixtures of $\mathrm{CL}$ and either $c(\mathrm{HT})_{2-5}$ or $c(\mathrm{HT})_{6-7}$ recorded by DSC and TGA analysis are compared in Table 4 , where corresponding data for the parent homopolymers PHT and PCL obtained by the same procedure have been also included for comparison. The melting temperature and enthalpy for copolymers decreases following a similar trend indicating the disturbing effect exerted by the CL units on crystallization. The same effect was observed for copolyesters made by using the $c(\mathrm{HT})_{6-7}$ fraction. 
The DSC traces for copolymers obtained with both cyclic fractions are compared in Figure 8. Regardless of the microstructure of the copolymer, homogeneous segments are long enough to form crystallites with stable size in the range of compositions, except for 30/70 for both cyclic fractions and copolymer 50/50 obtained with $\mathrm{c}(\mathrm{HT})_{6-7}$. On the other hand, the copolymers obtained with $c(\mathrm{HT})_{2-5}$ present higher crystallinity than copolymers synthesized with $c(\mathrm{HT})_{6-7}$ fraction, although due to the difference in molecular weight is not possible to determine whether differences in melting temperature and crystallinity are the result of using a fraction of cycles or different molecular size. Copolyesters prepared from $c(\mathrm{HT})_{2-5}$ clearly show a $T_{\mathrm{g}}$ that decreases steadily from $1{ }^{\circ} \mathrm{C}$ (copolymer 90/10) down to $-53^{\circ} \mathrm{C}$ (copolymer 10/90) covering the whole range of values limited by the parent homopolymers PHT and PCL. These observations are explained taking into account the nearly random comonomer distribution present in the copolyesters with low $\mathrm{CL}$ content and assuming a good miscibility between the $\mathrm{HT}$ and $\mathrm{CL}$ blocks present in the copolyesters with high CL content. In these blocky copolyesters, only one of the constituents form sequences long enough as to be able to crystallize.

Valuable information for the potential of these copolyesters concerns their mechanical properties. These were evaluated by stress-strain assays and compared to PHT. Representative stress-strain plots are compared in Figure 9 and numerical values obtained from these assays are given in Table 4. Whereas PHT fractured in a brittle fashion with very low elongation at break, the copolymers were ductile with the Young's modulus decreasing and elongation at break increasing as the content in $\mathrm{CL}$ increased. As a result, materials with different mechanical properties to meet different applications can be obtained by adjusting the comonomer feed ratio.

\section{Conclusions}

Hexamethylene terephthalate cyclic oligomers were prepared by cyclo-depolymerization of PHT in dilute solution. The oligomeric fraction comprised from dimer to heptamer with the 2 to 5 unit cycles accounting for near $95 \%$ of the sample. This fraction could be polymerized to PHT but needing more time and producing polyester of lower molecular weight than when a fraction enriched in hexamer-heptamer cycles was used. Copolymerization of the 2-5 fractions with $\varepsilon$ caprolactone produced copolyesters with composition and microstructure similar to those prepared from the 6-7 fractions but with significantly lower molecular weight. Thermal properties of the copolyesters coming from either 2-5 or 6-7 fractions were almost undistinguishable. The 
overall conclusion of this work is that ring opening polymerization and copolymerization of cyclic hexamethylene terephthalate oligomers is favored for higher cycle sizes and that the structure and properties of the copolyesters are essentially similar in both cases except as molecular weight is concerned. The fact that copolyesters with low CL content presented a nearly random microstructure in both cases is accounted by the occurrence of extensive transesterification reaction taking place from the earliest stages of the copolymerization reaction; this thermodynamic equilibrium is more difficult to achieve for the copolyesters with high $\mathrm{CL}$ contents, which invariably show a rather blocky microstructure.

\section{Acknowledgements}

We thank the CICYT (Comisión Interministerial de Ciencia y Tecnología) of Spain for financial support (Grant MAT2006-13209-C02-02) and AGAUR for the Ph.D. grant awarded to Nathalie González-Vidal. The support given by La Seda de Barcelona SA (El Prat, Barcelona) is also gratefully acknowledged.

\section{Apendix A. Suplementary Data}

Suplementary data associated with this article can be found in the online version

\section{References}

[1] Mclntyre JE. In: Scheirs J, Long TE, editors. Modern polyesters: chemistry and technology of polyesters and copolyesters. Chichester, UK: John Wiley \& Sons; 2003. p. 3-24.

[2] Fradet A, Tessier M. In: Rogerts ME, Long TE, editors. Synthetic methods in step-growth polymers. New Jersey: Wiley-Interscience; 2003. p. 17-118.

[3] Brunelle DJ. In: Semlyen JA editor. Cyclic Polymers. New York: Kluwer Academic Publishers; 2000. p. 185-228.

[4] Nair LS, Laurencin CT. Biodegradable polymers as biomaterials. Prog Polym Sci 2007;32:762-98.

[5] Okada M. Chemical synthesis of biodegradable polymers. Prog Polym Sci 2002;27:87133.

[6] Kohn FE, Van Ommen JG, Feijen J. The mechanism of the ring-opening polymerization of lactide and glycolide. Eur Polym J 1983;19(12):1081-88. 
[7] Brunelle DJ, Bradt JE, Serth-Guzzo J. Semicrystalline polymers via ring-opening polymerization: preparation and polymerization of alkylene phthalate cyclic oligomers. Macromolecules 1998;31(15):4782-90.

[8] Hall AJ, Hodge P, McGrail CS. Synthesis of a series of cyclic oligo(alkylidene isophthalate)s by cyclo-depolymerisation. Polymer 2000;41:1239-49.

[9] Hodge P, Colquhoun HM. Recent work on entropically-driven ring-opening polymerizations: some potential applications. Polym Adv Technol 2005;16(2-3):84-94.

[10] Hodge P, Yang Z, Ben-Haida A, McGrail CS. Cyclo-depolymerisation of poly(ethylene naphthalene-2,6-dicarboxylate) and ring-opening polymerisations of the cyclic oligomers obtained. J Mater Chem 2000;10:1533-37.

[11] Awaja F, Pavel D. Recycling of PET. Eur Polym J 2005;41(7):1453-77.

[12] Youk, J. H.; Kambour P, MacKnight WJ. Polymerization of ethylene terephthalate cyclic oligomers with antimony trioxide. Macromolecules 2000;33:3594-99.

[13] Youk JH, Kambour P, MacKnight WJ. Polymerization of ethylene terephthalate cyclic oligomers with a cyclic dibutyltin initiator. Macromolecules 2000;33:3600-05.

[14] Brunelle D. Cyclic oligomer chemistry. J Polym Sci A: Polym Chem, 2008;46:1151-64.

[15] Rohm \& Haas Company. Poly(hexamethylene terephthalate)s U.S. Patent 1119804, 1968.

[16] David C, Lefèbvre X, Lefèvre C, Demarteau W, Loutz JM. Thermal behaviour of polyesters of hexanediol with terephthalic and isophthalic acids. Prog Org Coat 1999;35:45-54.

[17] Lefèbvre X, Koch MHJ, Reynaers H, David C. Thermal behavior of poly(hexamethylene terephthalate) oligomers. I. Melting behavior and morphology of the crystalline phase. $J$ Polym Sci B: Polym Phys 1999;37:1-18.

[18] Lefevre C, Villers D, Koch MHJ, David C. Synthesis and thermal characterization of crystalizable poly(caprolactone)/poly(hexamethylene terephthalate) block copolymer. Polymer 2001;42:8769-77.

[19] González-Vidal N, Martínez de llarduya A, Herrera V, Muñoz-Guerra S. Poly(hexamethylene terephthalate-co-caprolactone) copolyesters obtained by ring-opening polymerization. Macromolecules 2008;41(12):4136-46.

[20] Azuma N, Sanda F, Takata T, Endo T. Effect of ring size on the cationic ring-opening polymerization of cyclic sulfites 
[21] Tillier D, Lefebvre $H$, Tessier M, Blais JC, Fradet A. High temperature bulk reaction between poly(ethylene terephthalate) and lactones: $1 \mathrm{H}$ NMR and SEC/MALDI-TOF MS study. Macromol Chem Phys, 2004, 205, 581-591.

[22] Tessier M, Fradet A. Determination of the degree of randomness in condensation copolymers containing both symmetrical and unsymmetrical monomer units: a theoretical study. e-Polymers, 2003, 30, 1-18.

[23] Kamau SD, Hodge P, Williams RT, Stagnaro P, Conzatti. High throughput synthesis of polyesters using entropically driven ring-opening polymerizations. J Comb Chem, 2008, $10,644-654$.

\section{Legends to figures}

Scheme 1. Preparation of $c(\mathrm{HT})_{2-5}$ via cyclo-depolymerization and route leading to $\mathrm{PHT}$ and $\mathrm{COPHT}_{x} \mathrm{CL}_{y}$ by ring opening polymerization of $c(\mathrm{HT})_{2-5}$ oligomers and $\mathrm{CL}$.

Figure 1. a) HPLC chromatogram of the cyclic oligomer fraction obtained by cyclodepolymerization of PHT in solution. b) MALDI-TOF mass spectra of individual species present in the oligomer cyclic fraction ( $\mathrm{C} 2$ to $\mathrm{C} 7$ from top to bottom).

Figure 2. a) Evolution of intrinsic viscosity and dimer content with reaction time. b) ${ }^{1} \mathrm{H}-\mathrm{NMR}$ spectra in the aromatic region of PHT obtained from $c(\mathrm{HT})_{2-5}$ with reaction time. c) Influence of cycle sizes on ROP of $c(\mathrm{HT})_{\mathrm{n}}$ in the intrinsic viscosity with reaction time.

Figure 3. DSC thermograms of $c(\mathrm{HT})_{2-5}(\mathrm{a})$ and $c(\mathrm{HT})_{6-7}(\mathrm{~b})$. c) Increase of average molecular weights with reaction time of $c(\mathrm{HT})_{2-5} \mathrm{ROP}$ without catalyst.

Figure 4. Evolution of the weight-average molecular weight of ${ }^{\circ O P H T}{ }_{50} \mathrm{CL}_{50}$ as a function of reaction time for the two cyclic oligomer fractions.

Figure 5. ${ }^{1} \mathrm{H}-\mathrm{NMR}$ spectrum of $\mathrm{COPHT}_{50} \mathrm{CL}_{50}$ recorded in $\mathrm{CDCl}_{3} / \mathrm{TFA} 9 / 1$ with peak assignments.

Figure 6. a) ${ }^{13} \mathrm{C}-\mathrm{NMR}$ spectra of $\mathrm{coPHT}_{x} \mathrm{CL}_{y}$ and b) $\mathrm{coPHT}_{50} \mathrm{CL}_{50}$ at different reaction times recorded in $\mathrm{CDCl}_{3} / \mathrm{TFA} 9 / 1$ with triad sequence assignment in the region of $\beta-\mathrm{CH}_{2}$ of hexamethylene units and $\delta$ and $\varepsilon-\mathrm{CH}_{2}$ of $\mathrm{CL}$ units.

Figure 7. Evolution of the randomness of $\mathrm{COPHT}_{50} \mathrm{CL}_{50}$ as a function of reaction time for the two cyclic oligomer fractions.

Figure 8. DSC heating thermograms recorded from $\mathrm{cOPHT}_{x} \mathrm{CL}_{\mathrm{y}}$ synthesized from mixtures of $\mathrm{CL}$ and $c(\mathrm{HT})_{2-5}(\mathrm{a})$ or $c(\mathrm{HT})_{6-7}(\mathrm{~b})$.

Figure 9. Compared stress-strain curves for copolyesters $\operatorname{coPHT}_{x} \mathrm{CL}_{y}$. 
Table 1

Cyclo-depolymerization of PHT.

\begin{tabular}{|c|c|c|c|c|c|c|c|c|}
\hline \multirow{2}{*}{$\begin{array}{l}\text { PHT/DCB } \\
\left(\mathrm{mol} \cdot \mathrm{L}^{-1}\right)\end{array}$} & \multirow{2}{*}{$\begin{array}{c}t \\
\text { (days) }\end{array}$} & \multirow{2}{*}{$\begin{array}{c}\text { Yield } \\
(\% \mathrm{w} / \mathrm{w})\end{array}$} & \multicolumn{6}{|c|}{ Yields (\%- weight) of cyclic $n$-mers ${ }^{a}$} \\
\hline & & & $\mathrm{n}=2$ & $\mathrm{n}=3$ & $\mathrm{n}=4$ & $n=5$ & $\mathrm{n}=6$ & $\mathrm{n}=7$ \\
\hline 0.1 & 2 & 43 & 44.2 & 27.5 & 14.9 & 8.2 & 3.3 & 1.9 \\
\hline 0.1 & 4 & 85 & 43.8 & 27.5 & 15.6 & 6.2 & 3.8 & 2.9 \\
\hline 0.1 & 8 & 92 & 44.9 & 26.8 & 15.2 & 8.0 & 3.2 & 1.8 \\
\hline 0.06 & 4 & 90 & 43.4 & 27.8 & 15.5 & 8.2 & 3.1 & 1.9 \\
\hline
\end{tabular}

Table 2

Ring opening polymerization of $c(\mathrm{HT})_{\mathrm{n}}$ for $120 \mathrm{~min}$.

\begin{tabular}{|c|c|c|c|c|}
\hline Catalyst $^{a}$ & $n^{b}$ & $T\left({ }^{\circ} \mathrm{C}\right)$ & $\begin{array}{c}c(\mathrm{HT})_{2}{ }^{\mathrm{c}} \\
(\%-\mathrm{mole})\end{array}$ & $\begin{array}{c}{[\eta]^{\mathrm{d}}} \\
\left(\mathrm{dL} \cdot \mathrm{g}^{-1}\right)\end{array}$ \\
\hline $\mathrm{-e}^{\mathrm{e}}$ & $2-5$ & $-{ }^{e}$ & $43.8^{e}$ & 0.09 \\
\hline none & $2-5$ & 200 & 19.8 & 0.17 \\
\hline \multirow[t]{3}{*}{$\mathrm{Sb}_{2} \mathrm{O}_{3}$} & $2-5$ & 175 & 12.1 & 0.26 \\
\hline & $2-5$ & 200 & 2.2 & 0.54 \\
\hline & $6-7$ & 200 & - & 0.67 \\
\hline \multirow[t]{2}{*}{ DBTO } & $2-5$ & 175 & 13.2 & 0.26 \\
\hline & $2-5$ & 200 & 2.5 & 0.46 \\
\hline \multirow[t]{2}{*}{$\mathrm{Sn}(\mathrm{Oct})_{2}$} & $2-5$ & 175 & 13.6 & 0.33 \\
\hline & $2-5$ & 200 & 2.1 & 0.54 \\
\hline
\end{tabular}


Table 3

Composition, average sequence lengths and randomness of $\operatorname{coPHT}_{x} \mathrm{CL}_{y}$ copolyesters. ${ }^{a}$

\begin{tabular}{|c|c|c|c|c|c|c|c|c|c|}
\hline \multirow[b]{2}{*}{ Copolyester } & \multirow[b]{2}{*}{$t(\min )$} & \multirow[b]{2}{*}{$\mathrm{n}$} & \multicolumn{2}{|c|}{ Composition $^{\mathrm{b}}$} & \multicolumn{3}{|c|}{ Triads content ${ }^{\mathrm{c}}(\mathrm{mol} \%)$} & \multirow[b]{2}{*}{$a^{c}$} & \multirow{2}{*}{$\begin{array}{c}\text { Randomness }^{\mathrm{d}} \\
(B)\end{array}$} \\
\hline & & & $x_{\mathrm{HT}}$ & $x_{\mathrm{CL}}$ & $\mathrm{THT}$ & $\mathrm{THCL}$ & $\mathrm{CLHCL}$ & & \\
\hline \multirow[t]{2}{*}{$\operatorname{coPHT}_{90} \mathrm{CL}_{10}$} & 120 & $2-5$ & 90.2 & 9.8 & 89.6 & 10.4 & 0 & 0.95 & 1.03 \\
\hline & & $6-7$ & 92.1 & 7.9 & 91.8 & 8.2 & 0 & 0.96 & 1.01 \\
\hline \multirow{2}{*}{${ }_{c o P H T}{ }_{70} \mathrm{CL}_{30}$} & 120 & $2-5$ & 77.1 & 22.8 & 78.5 & 19.6 & 1.9 & 0.89 & 0.90 \\
\hline & & $6-7$ & 73.7 & 26.3 & 77.1 & 19.8 & 3.1 & 0.87 & 0.83 \\
\hline \multirow[t]{8}{*}{${ }_{c o P H T}{ }_{50} \mathrm{CL}_{50}$} & 30 & $2-5$ & 51.5 & 48.5 & 89.4 & 10.6 & 0.5 & 0.95 & 0.17 \\
\hline & & $6-7$ & 46.9 & 53.1 & 58.4 & 38.0 & 3.6 & 0.77 & 0.64 \\
\hline & 60 & $2-5$ & 50.7 & 49.3 & 65.6 & 30.6 & 3.8 & 0.81 & 0.58 \\
\hline & & $6-7$ & 45.5 & 54.4 & 55.8 & 37.0 & 7.2 & 0.74 & 0.68 \\
\hline & 90 & $2-5$ & 49.7 & 50.3 & 58.6 & 35.7 & 5.7 & 0.77 & 0.70 \\
\hline & & $6-7$ & 46.9 & 53.2 & 52.6 & 39.7 & 7.7 & 0.73 & 0.76 \\
\hline & 120 & $2-5$ & 52.7 & 47.3 & 53.6 & 39.0 & 7.2 & 0.73 & 0.87 \\
\hline & & $6-7$ & 51.0 & 49.0 & 53.2 & 39.2 & 7.6 & 0.73 & 0.84 \\
\hline \multirow[t]{2}{*}{${ }_{c o P H T}{ }_{30} \mathrm{CL}_{70}$} & 120 & $2-5$ & 33.4 & 66.6 & 45.0 & 18.0 & 25.0 & 0.61 & 0.79 \\
\hline & & $6-7$ & 25.1 & 74.9 & 26.7 & 46.9 & 26.4 & 0.51 & 0.82 \\
\hline \multirow[t]{2}{*}{$\mathrm{coPHT}_{10} \mathrm{CL}_{90}$} & 120 & $2-5$ & 10.5 & 89.5 & 39.6 & 45.5 & 14.9 & 0.63 & 0.46 \\
\hline & & $6-7$ & 9.9 & 90.1 & 39.6 & 45.5 & 14.9 & 0.63 & 0.46 \\
\hline
\end{tabular}

${ }^{a}$ Copolyesters obtained at $175^{\circ} \mathrm{C}$ and $0.5 \mathrm{~mol} \% \mathrm{Sb}_{2} \mathrm{O}_{3}$ catalyst .

${ }^{\mathrm{b}}$ Determined from ${ }^{1} \mathrm{H}$ NMR spectra.

${ }^{\mathrm{c}}$ Determined by deconvolution of the $\beta$-methylene signals of the hexamethylene units observed in the ${ }^{13} \mathrm{C}$ NMR spectra.

${ }^{d}$ The values of $a$ and randomness were calculated by applying the expressions given in the text. 
Table 4

Molecular weights and thermal and mechanical properties of $\operatorname{coPHT}_{x} \mathrm{CL}_{y}$ copolyesters. ${ }^{a}$

\begin{tabular}{|c|c|c|c|c|c|c|c|c|c|}
\hline \multirow[t]{2}{*}{ Copolyester } & \multirow[b]{2}{*}{$n^{b}$} & \multicolumn{2}{|c|}{ GPC } & \multicolumn{4}{|c|}{ DSC and TGA } & \multicolumn{2}{|c|}{ Tensile test } \\
\hline & & $M w^{c}$ & $P D^{C}$ & $\begin{array}{c}T_{\mathrm{g}}^{\mathrm{d}} \\
\left({ }^{\circ} \mathrm{C}\right)\end{array}$ & $\begin{array}{c}T_{\mathrm{m}}^{\mathrm{e}} \\
\left({ }^{\circ} \mathrm{C}\right)\end{array}$ & $\begin{array}{l}\Delta H_{\mathrm{m}}^{\mathrm{e}} \\
\left(\mathrm{J} \cdot \mathrm{g}^{-1}\right)\end{array}$ & $\begin{array}{l}{ }^{\circ} T_{d}^{f} \\
\left({ }^{\circ} \mathrm{C}\right)\end{array}$ & $\begin{array}{c}E \\
(\mathrm{MPa})^{\mathrm{g}}\end{array}$ & $\begin{array}{c}\varepsilon_{\text {break }}{ }^{g} \\
(\%)\end{array}$ \\
\hline PHT & $\begin{array}{l}2-5 \\
6-7\end{array}$ & $\begin{array}{l}39,000 \\
50,300\end{array}$ & $\begin{array}{l}2.0 \\
2.1\end{array}$ & $\begin{array}{c}9 \\
11\end{array}$ & $\begin{array}{l}143 \\
143\end{array}$ & $\begin{array}{l}36 \\
36\end{array}$ & $\begin{array}{l}382 \\
385\end{array}$ & 620.1 & 2.2 \\
\hline $\operatorname{coPHT}_{90} \mathrm{CL}_{10}$ & $\begin{array}{l}2-5 \\
6-7\end{array}$ & $\begin{array}{l}38,300 \\
55,200\end{array}$ & $\begin{array}{l}1.9 \\
2.1\end{array}$ & $\begin{array}{l}1 \\
4\end{array}$ & $\begin{array}{l}133 \\
131\end{array}$ & $\begin{array}{l}36 \\
32\end{array}$ & $\begin{array}{l}380 \\
385\end{array}$ & 488.8 & 9.5 \\
\hline $\mathrm{coPHT}_{70} \mathrm{CL}_{30}$ & $\begin{array}{l}2-5 \\
6-7\end{array}$ & $\begin{array}{l}35,800 \\
50,200\end{array}$ & $\begin{array}{l}2.1 \\
2.0\end{array}$ & $\begin{array}{l}-17 \\
-16\end{array}$ & $\begin{array}{c}119 \\
82\end{array}$ & $\begin{array}{l}28 \\
19\end{array}$ & $\begin{array}{l}371 \\
369\end{array}$ & 311.7 & 12.7 \\
\hline $\mathrm{coPHT}_{50} \mathrm{CL}_{50}$ & $\begin{array}{l}2-5 \\
6-7\end{array}$ & $\begin{array}{l}32,900 \\
53,400\end{array}$ & $\begin{array}{l}2.0 \\
2.0\end{array}$ & $\begin{array}{l}-38 \\
-32\end{array}$ & $\begin{array}{c}79 \\
\text { n.o. }\end{array}$ & $\begin{array}{c}20 \\
\text { n.o. }\end{array}$ & $\begin{array}{l}364 \\
372\end{array}$ & 75.6 & 13.5 \\
\hline $\mathrm{coPHT}_{30} \mathrm{CL}_{70}$ & $\begin{array}{l}2-5 \\
6-7\end{array}$ & $\begin{array}{l}33,700 \\
38,200\end{array}$ & $\begin{array}{l}2.0 \\
2.0\end{array}$ & $\begin{array}{l}-48 \\
-44\end{array}$ & $\begin{array}{l}\text { n.o. } \\
\text { n.o. }\end{array}$ & $\begin{array}{l}\text { n.o. } \\
\text { n.o. }\end{array}$ & $\begin{array}{l}358 \\
330\end{array}$ & 27.6 & 20.8 \\
\hline $\operatorname{coPHT}_{10} \mathrm{CL}_{90}$ & $\begin{array}{l}2-5 \\
6-7\end{array}$ & $\begin{array}{l}31,300 \\
40,800\end{array}$ & $\begin{array}{l}1.9 \\
1.8\end{array}$ & $\begin{array}{l}-53 \\
-51\end{array}$ & $\begin{array}{l}42 \\
56\end{array}$ & $\begin{array}{l}46 \\
54\end{array}$ & $\begin{array}{l}340 \\
332\end{array}$ & - & - \\
\hline $\mathrm{PCL}^{\mathrm{a}}$ & - & 32,900 & 1.7 & -60 & 60 & 90 & 377 & - & - \\
\hline
\end{tabular}

${ }^{\mathrm{a}} \mathrm{PHT}$ and copolyesters obtained at $175^{\circ} \mathrm{C}$ for $120 \mathrm{~min}$ and $0.5 \mathrm{~mol} \% \mathrm{Sb}_{2} \mathrm{O}_{3}$ catalyst . Reaction time for PCL (48h).

${ }^{\mathrm{b}}$ Cyclic size.

${ }^{\mathrm{c}}$ Weight-average molecular weight and polydispersity determined by GPC

${ }^{d}$ Glass transition temperature from melt-quenched samples determined by DSC at $20^{\circ} \mathrm{C} \cdot \mathrm{min}^{-1}$.

${ }^{e}$ Melting temperature and enthalpy determined by DSC on the second heating at $10^{\circ} \mathrm{C} \cdot \mathrm{min}^{-1}$.

${ }^{f}$ Maximum rate decomposition temperatures determined by TGA under inert atmosphere.

${ }^{g}$ Young modulus and elongation at break determined by tensile test. 


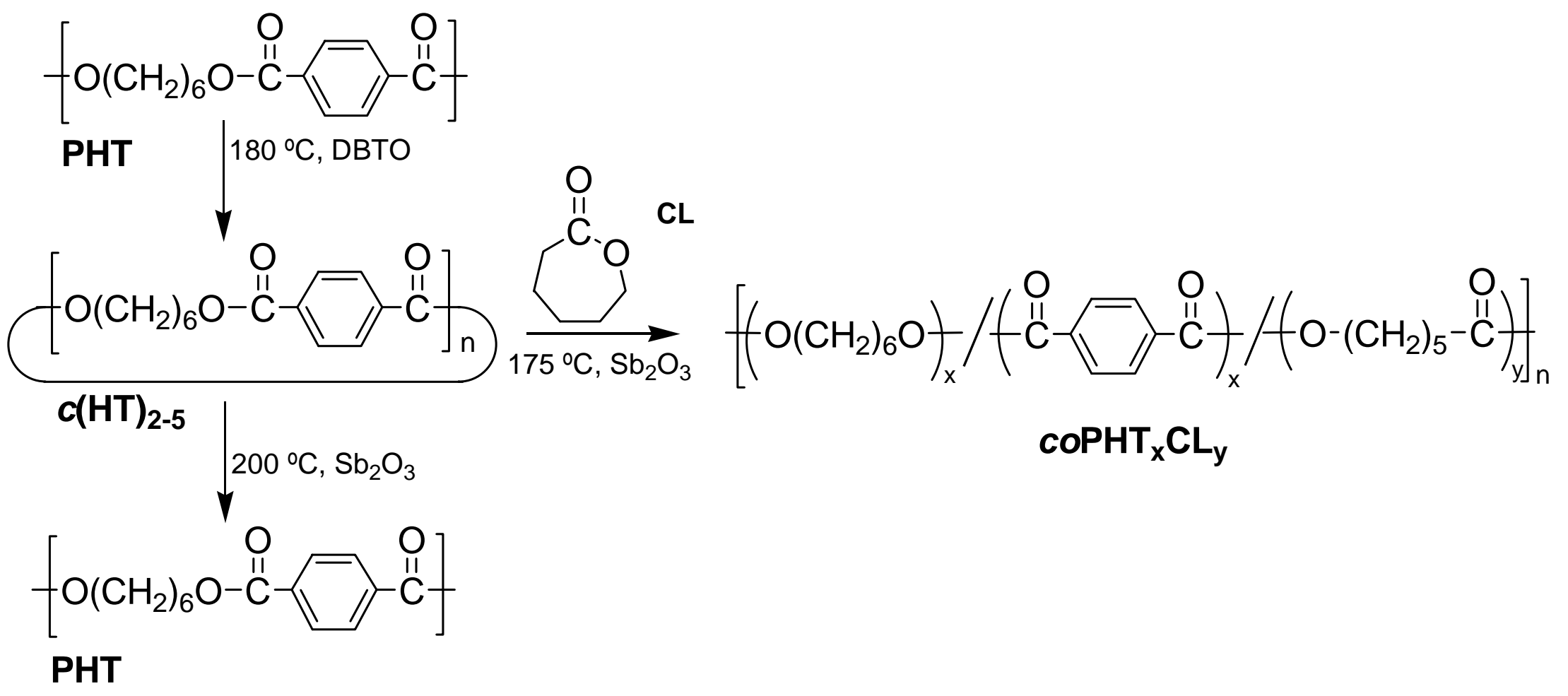

Scheme 1 


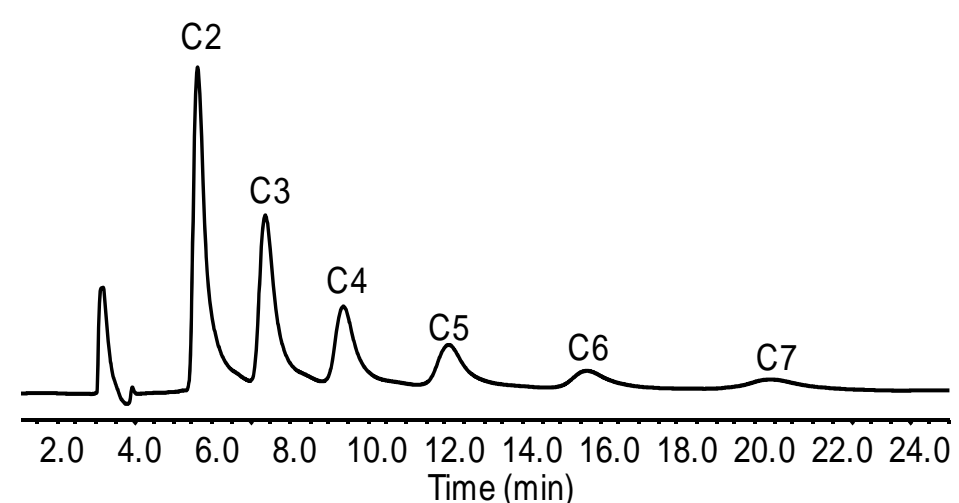

a)
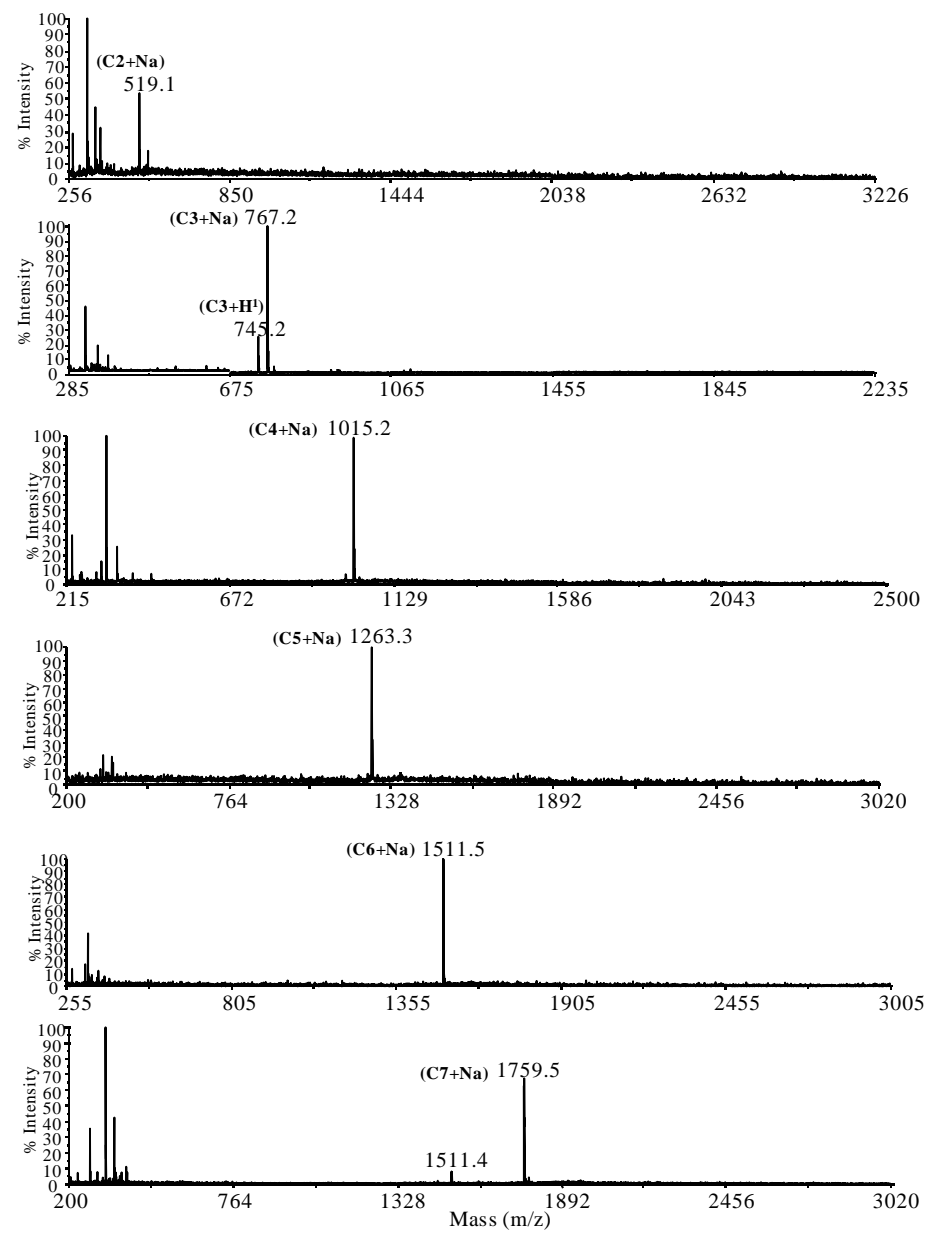

b)

Figure 1 


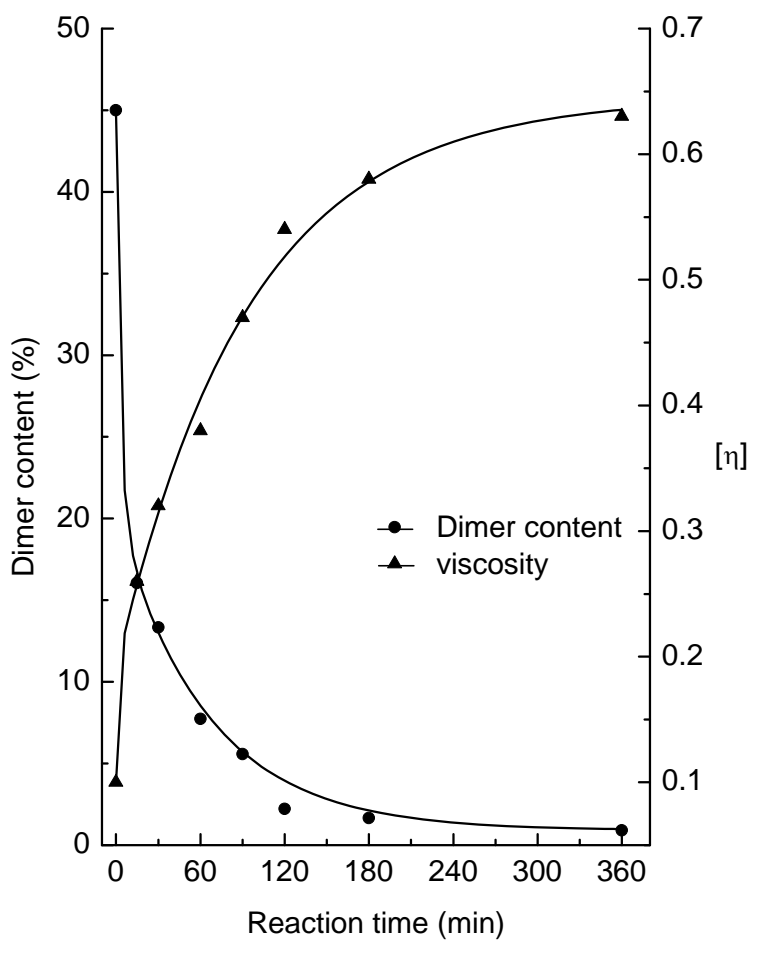

a)

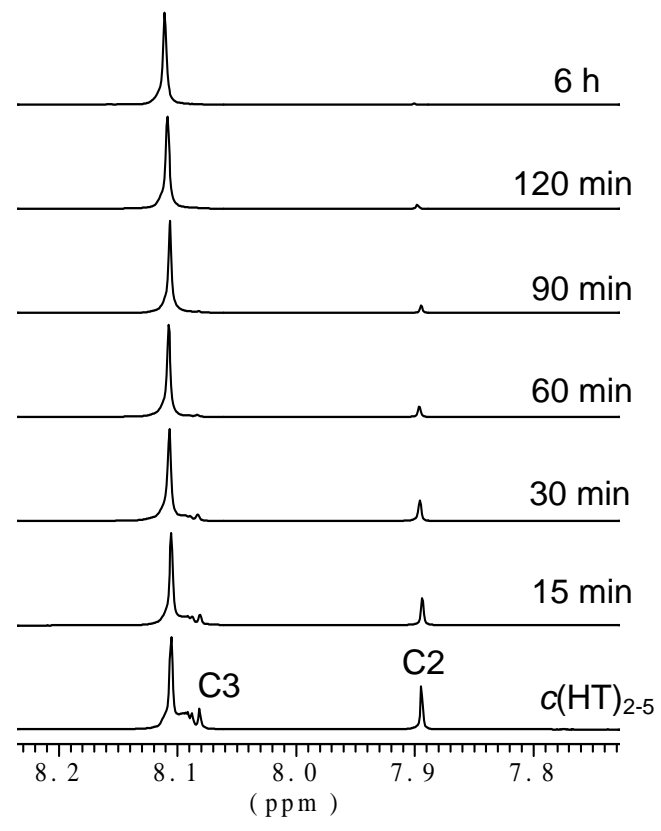

b)

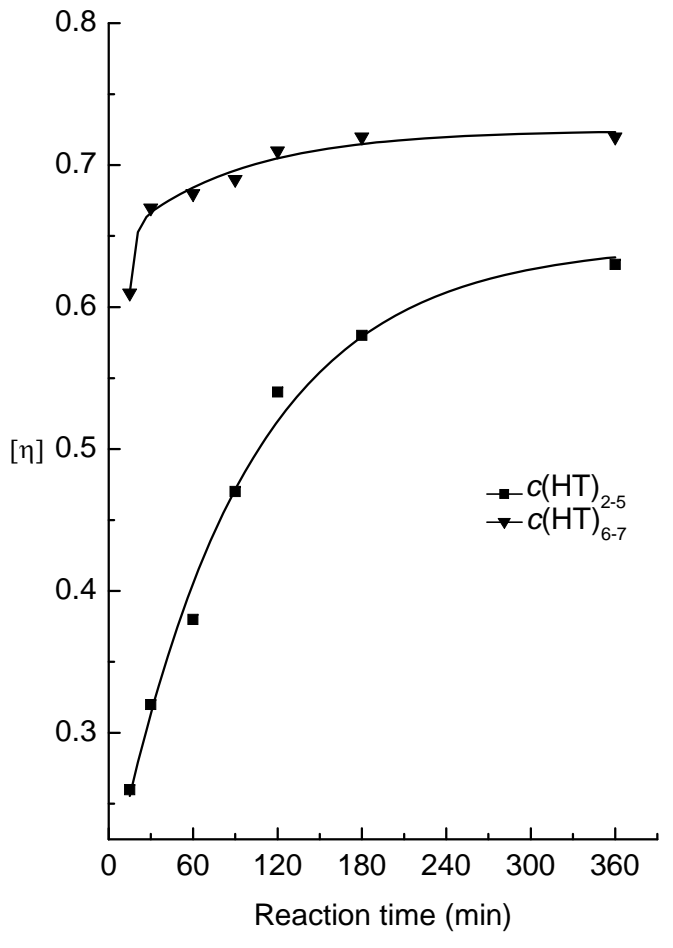

c)

Figure 2 


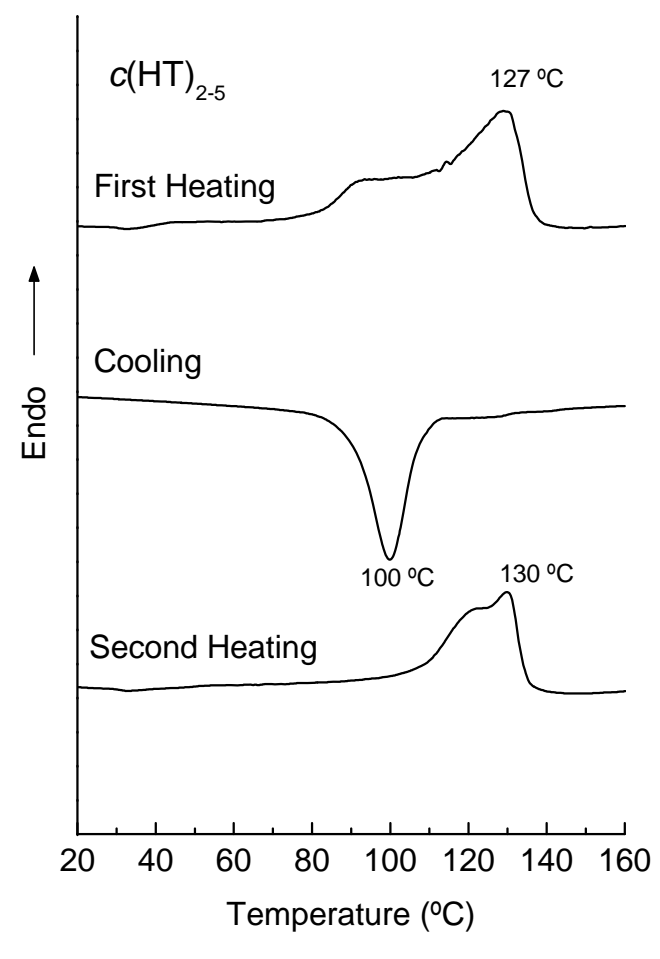

a)

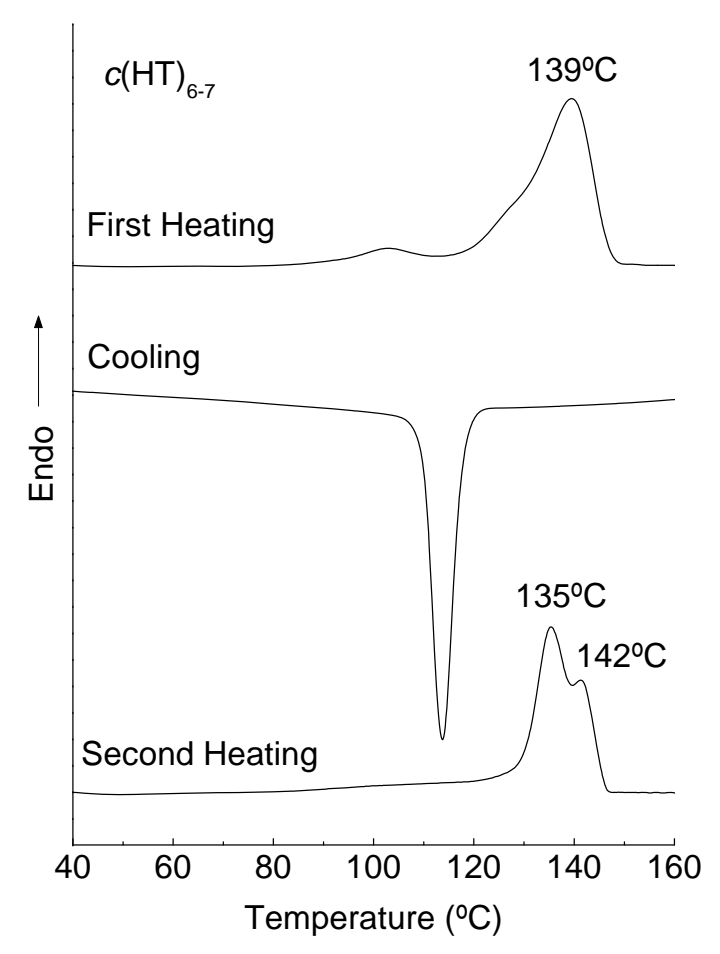

b)

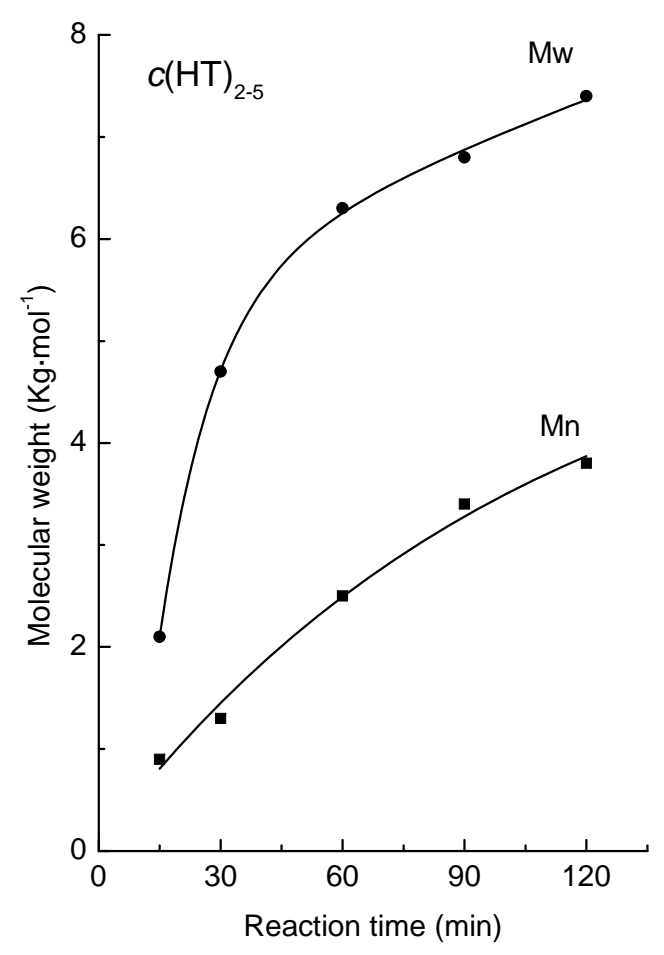

c)

Figure 3 


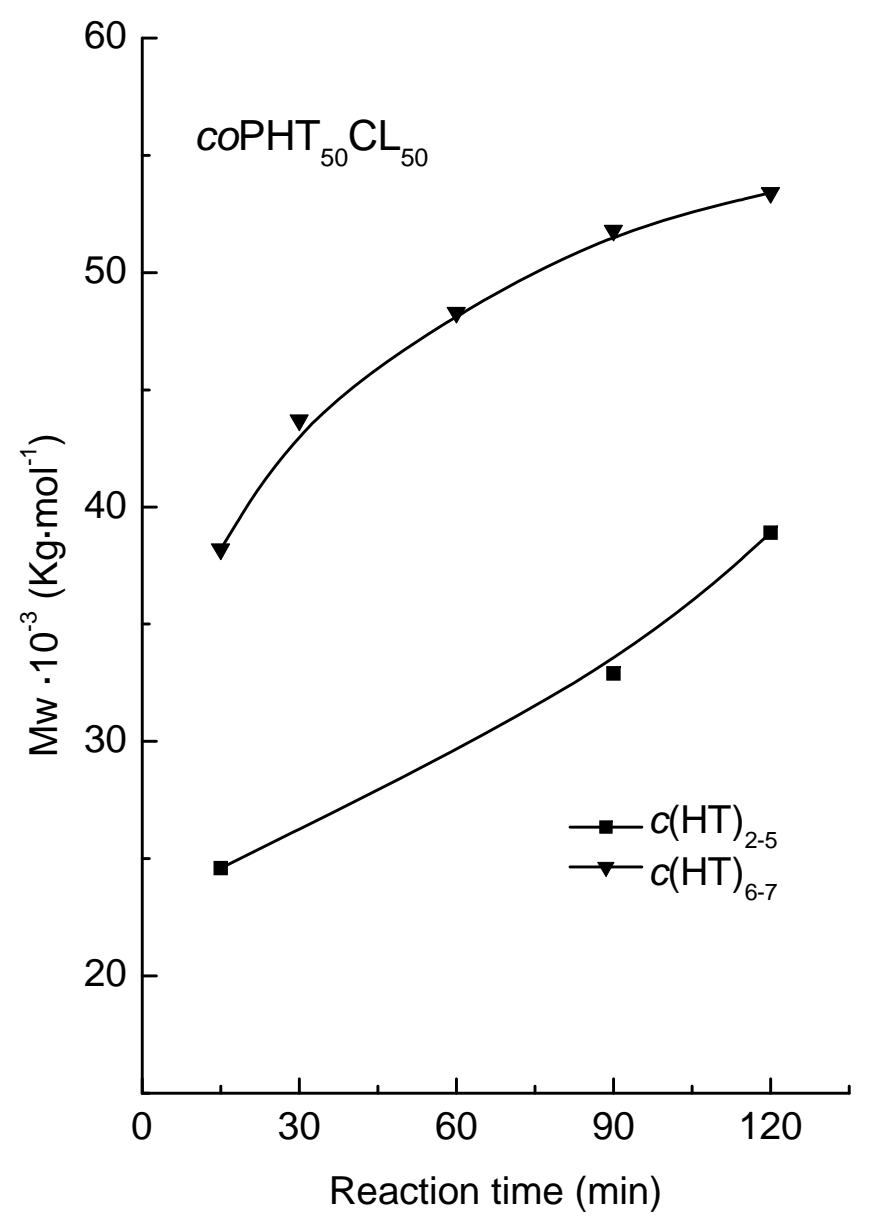

Figure 4 


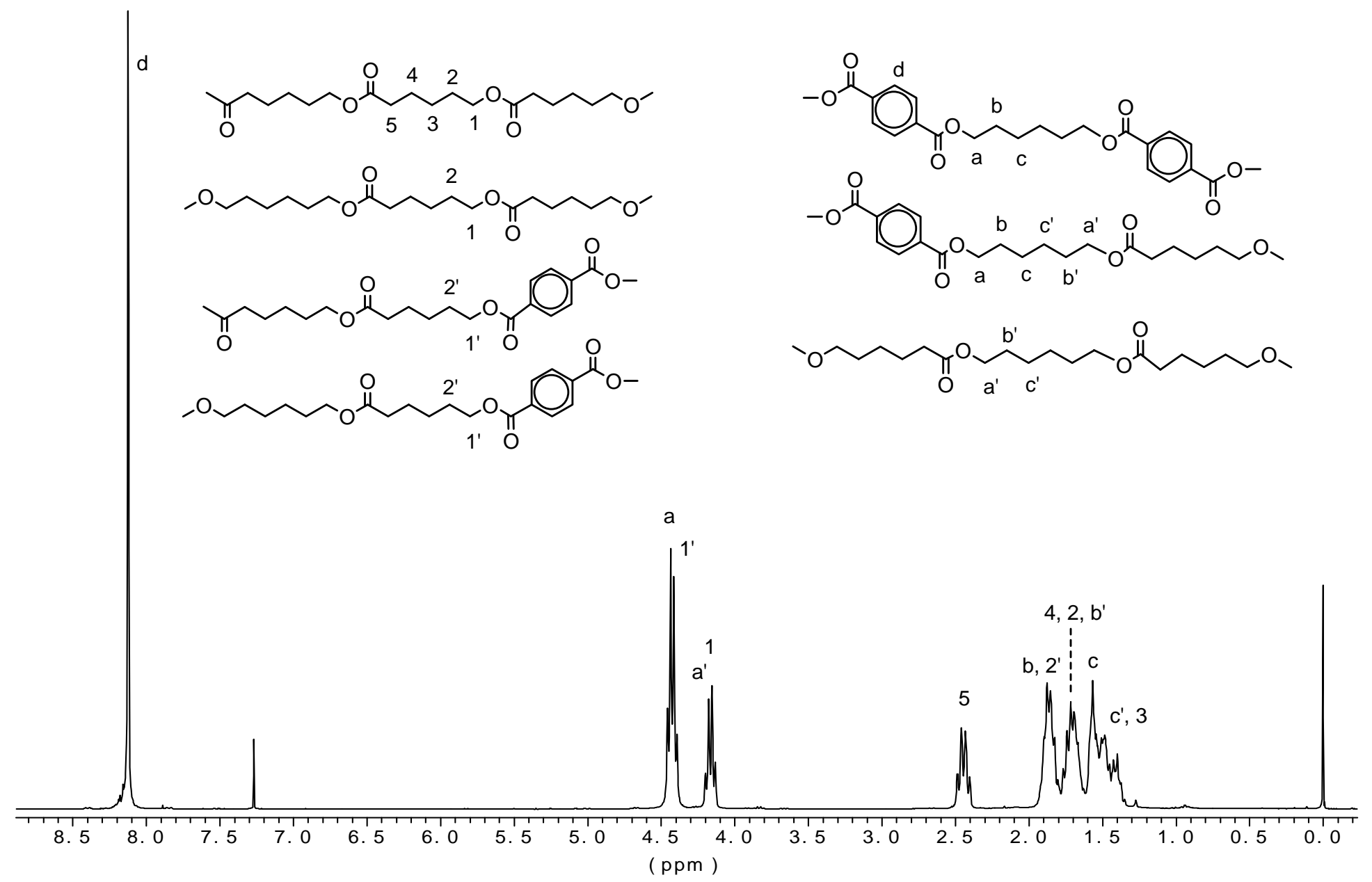

Figure 5 
a)
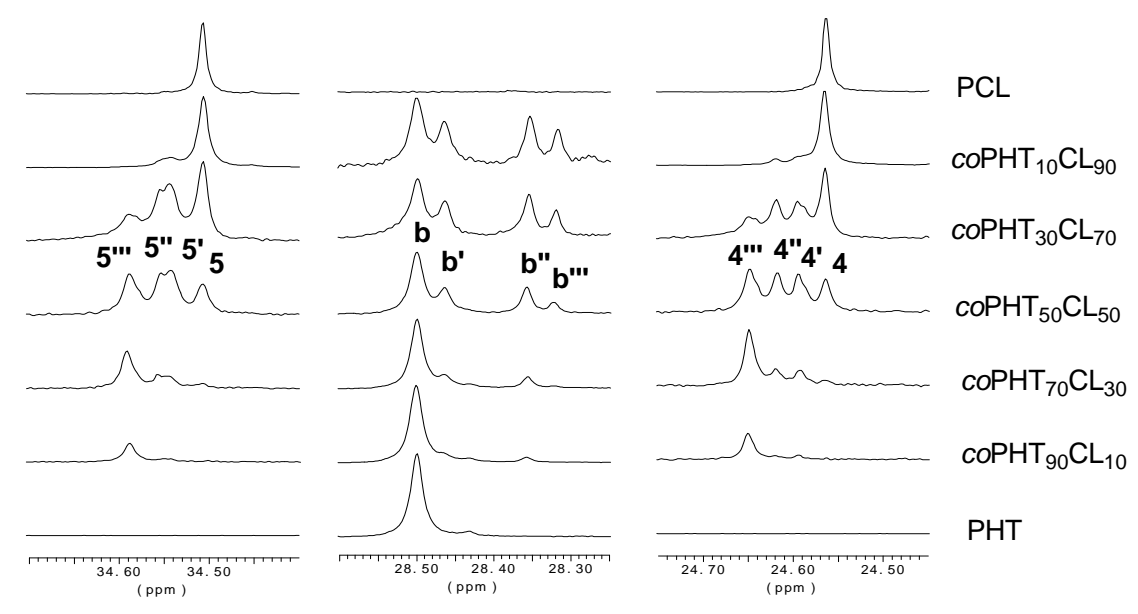

b)

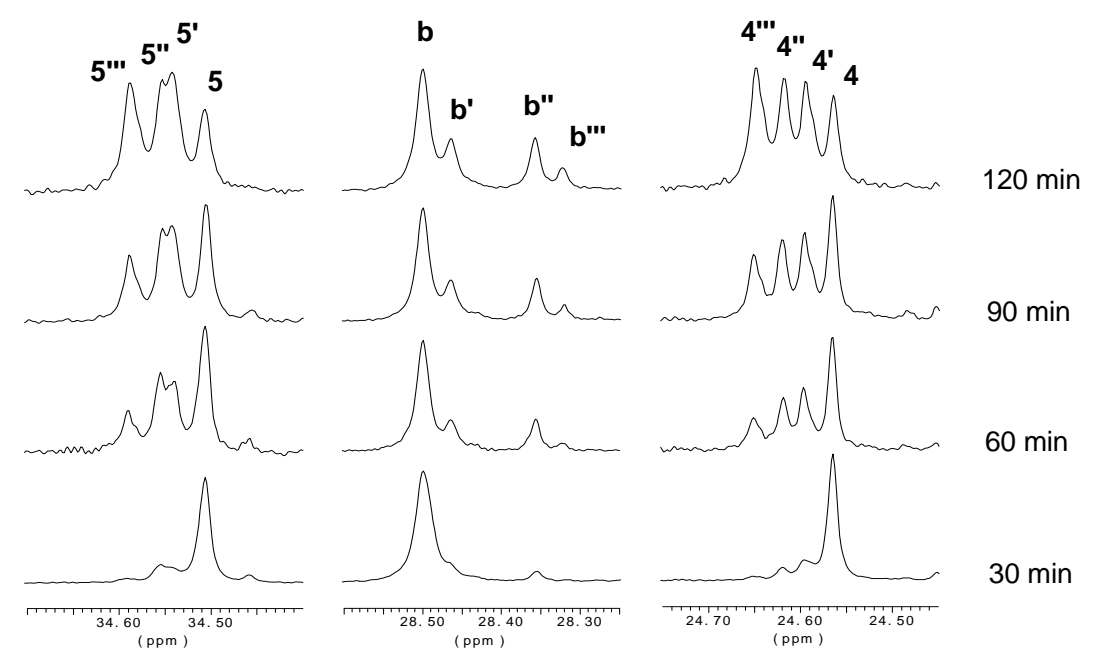

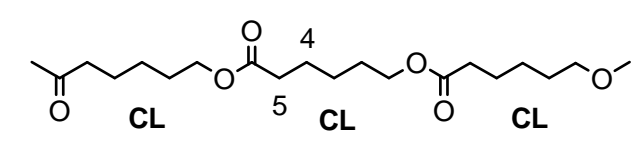

$\sim_{\mathrm{H}}^{\mathrm{O}} \overbrace{5^{\prime} \mathrm{CL}}^{\mathrm{H}^{4}} \overbrace{\mathrm{O}_{\mathrm{CL}_{\mathrm{O}}}}^{\mathrm{O}^{\prime}}$
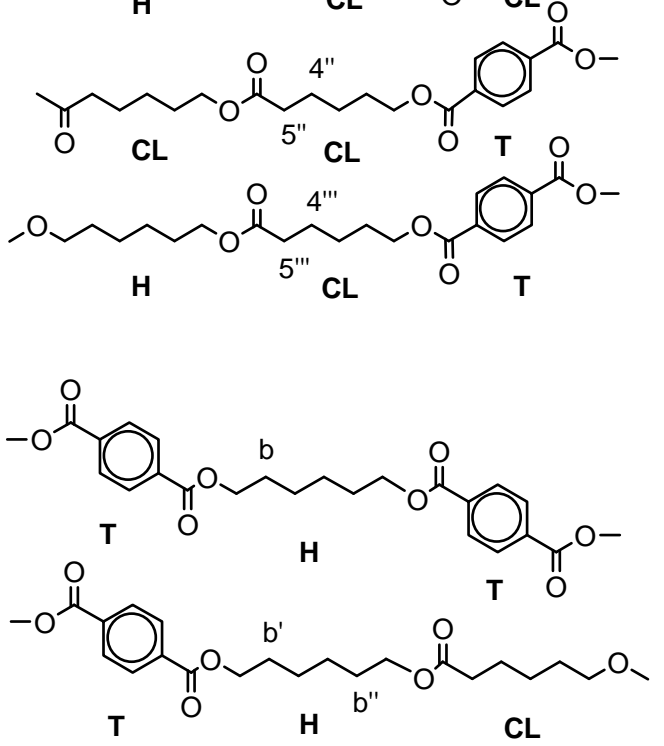

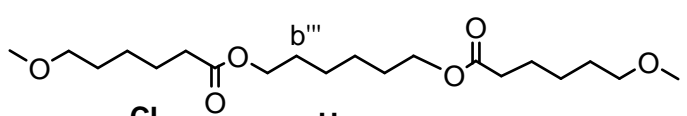

CL

\section{Figure 6}




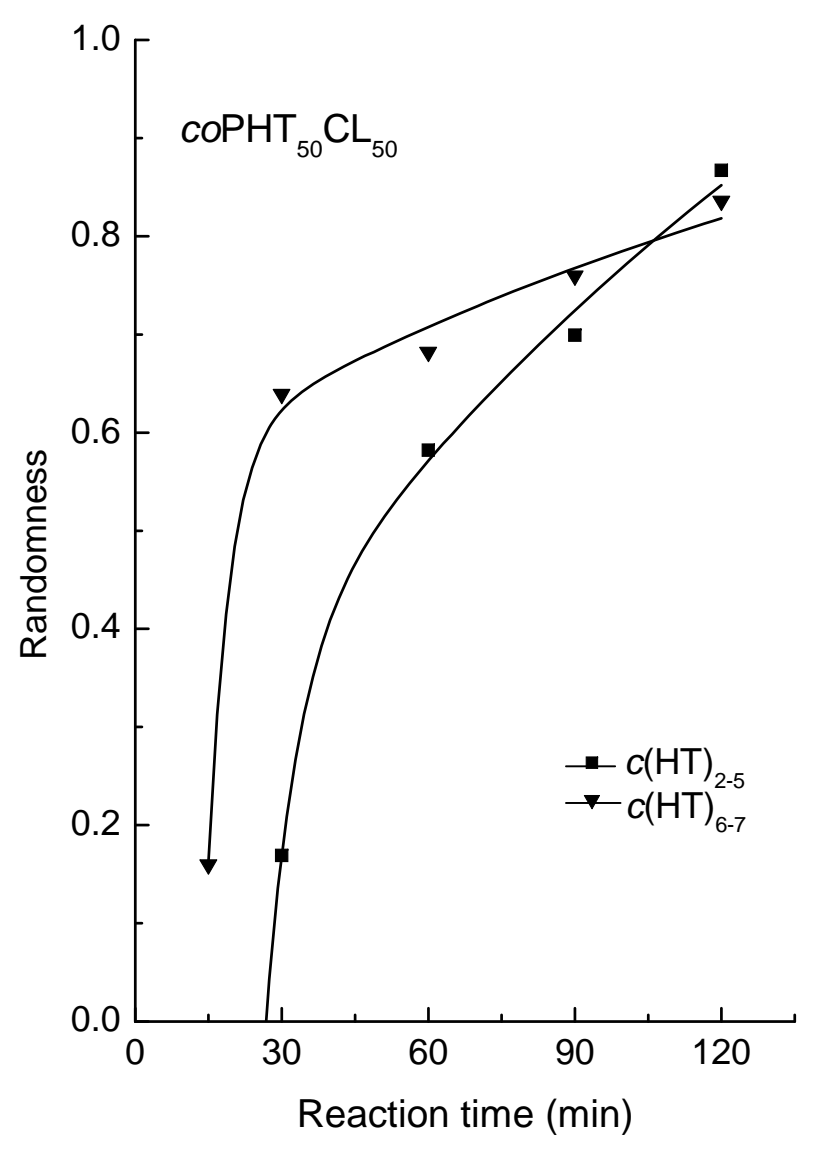

Figure 7 


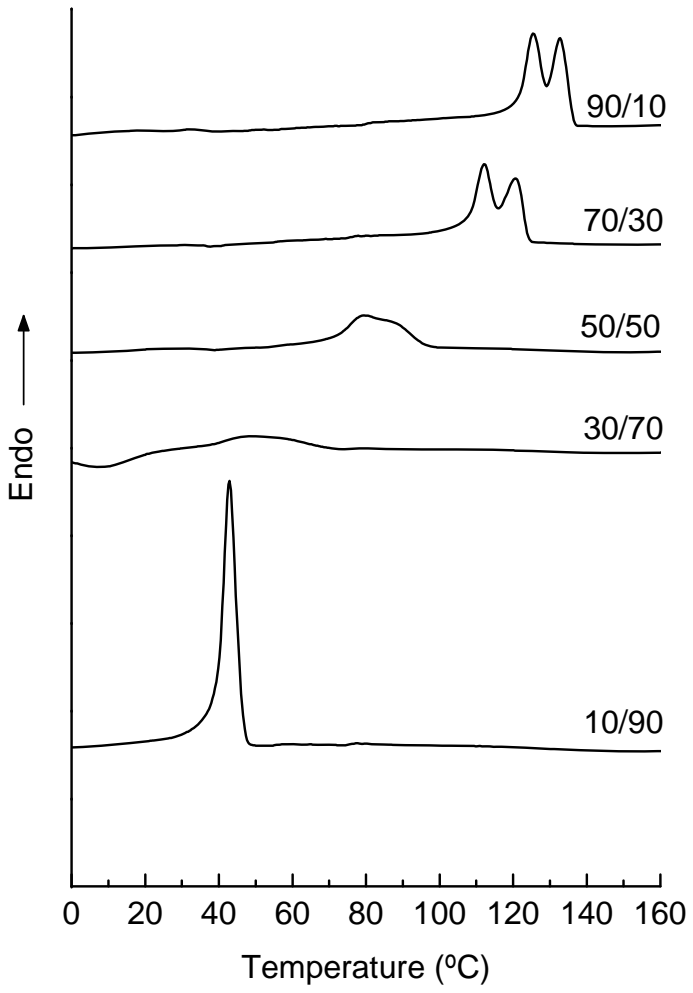

a)

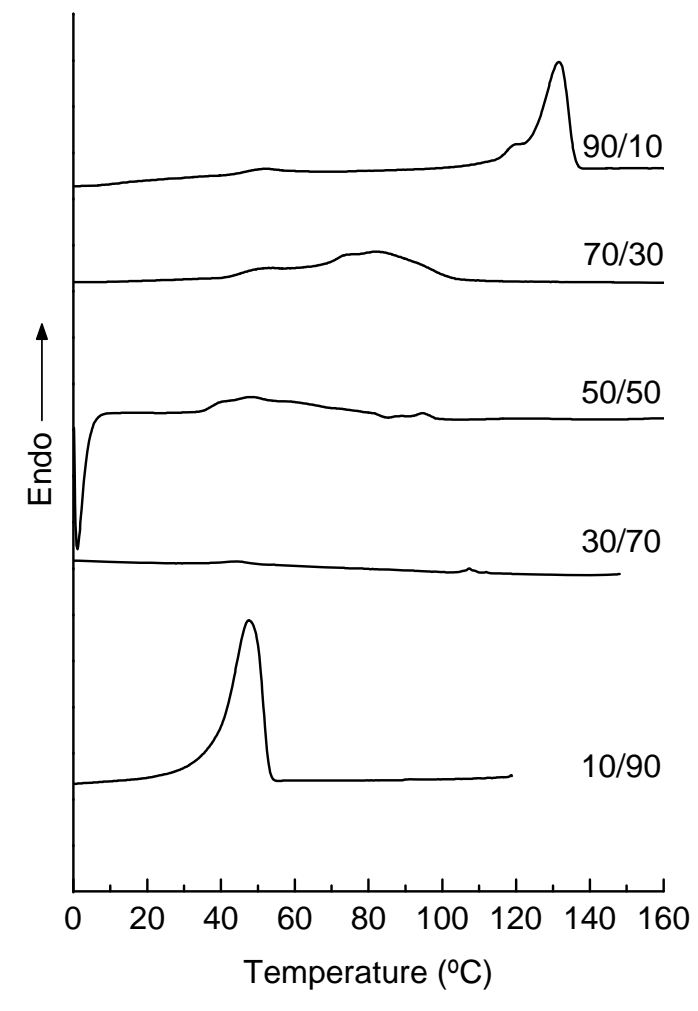

b)

Figure 8 


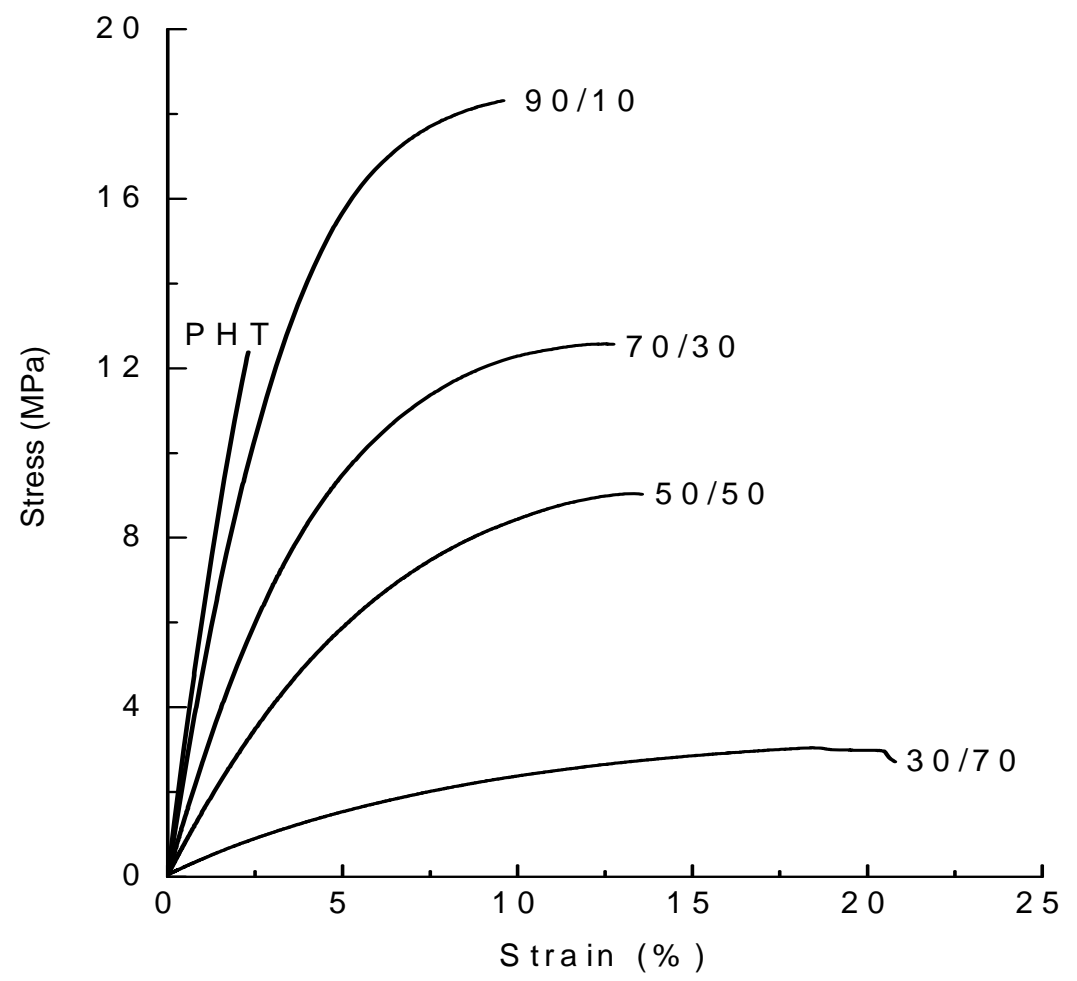

Figure 9 


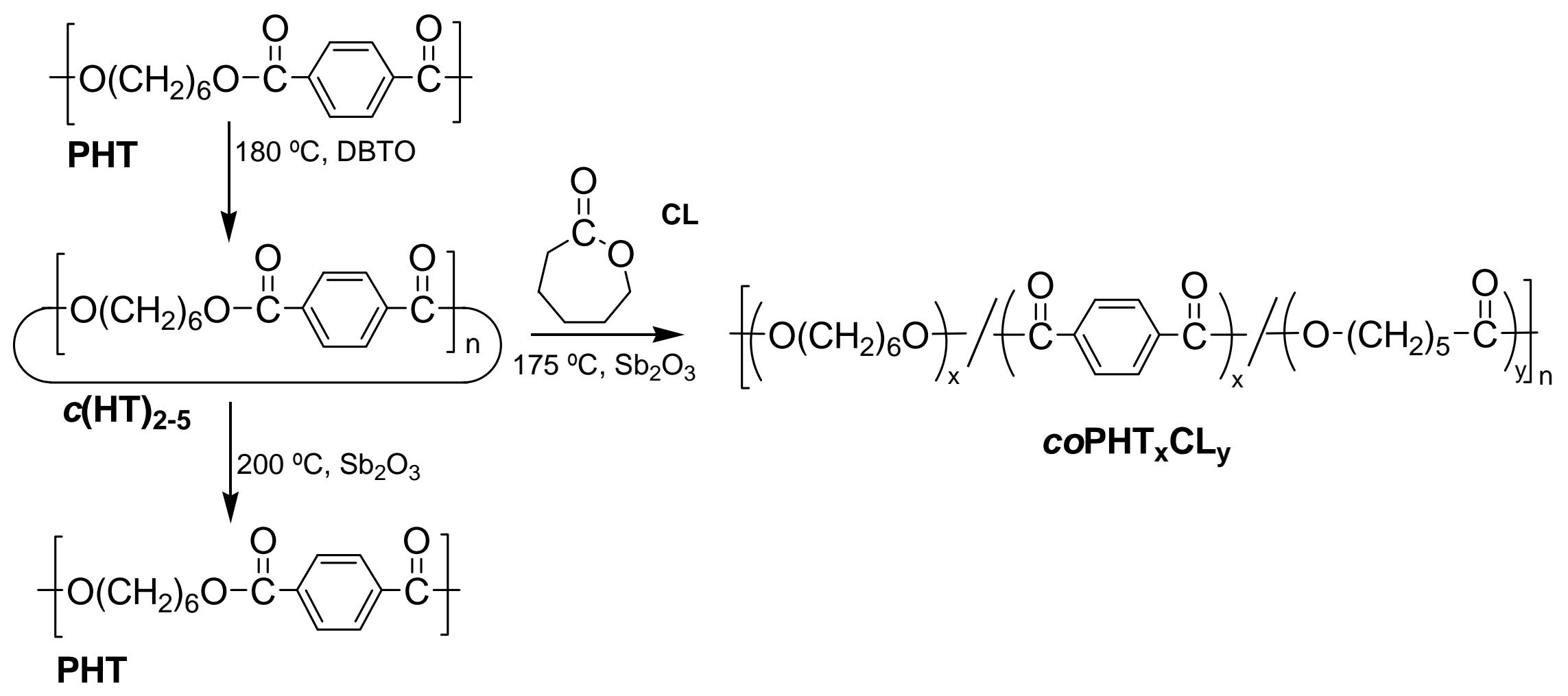




\section{Supporting Information}

Poly(hexamethylene terephthalate-co-caprolactone) copolymers: Influence of cycle size on ring-opening polymerization

Nathalie González-Vidal, Antxon Martínez de llarduya, 'Sebastián Muñoz-Guerra.

Departament d'Enginyeria Química, Universitat Politècnica de Catalunya, ETSEIB, Diagonal 647, 08028 Barcelona, Spain

Content:

Fig. 1. a) ${ }^{13} \mathrm{C}-\mathrm{NMR}$ spectra of $\mathrm{coPHT}_{x} \mathrm{CL}_{y}$ and b) $\mathrm{coPHT}_{50} \mathrm{CL}_{50}$ obtained from $c(\mathrm{HT})_{6-7}$ cyclic oligomers and $\mathrm{CL}$ at different reaction times recorded in $\mathrm{CDCl}_{3 /} \mathrm{TFA} 9 / 1$ with triad sequence assignment in the region of $\alpha, \beta-\mathrm{CH}_{2}$ of hexamethylene units and $\delta$ and $\varepsilon-\mathrm{CH}_{2}$ of $\mathrm{CL}$ units.

Table 1. Compared degree of randomness of of $c o P H T_{x} C_{y}$ obtained from $c(H T)_{6-7}$ cyclic oligomers and $\mathrm{CL}$ taken from ref. 19 and the recalculated ones using the new methodology proposed in the text [22].

* Corresponding author: Tel. +34 934010910; Fax. +34 934017150

E-mail address: antxon.martinez.de.ilarduia@upc.edu (A. Martínez de llarduya) 

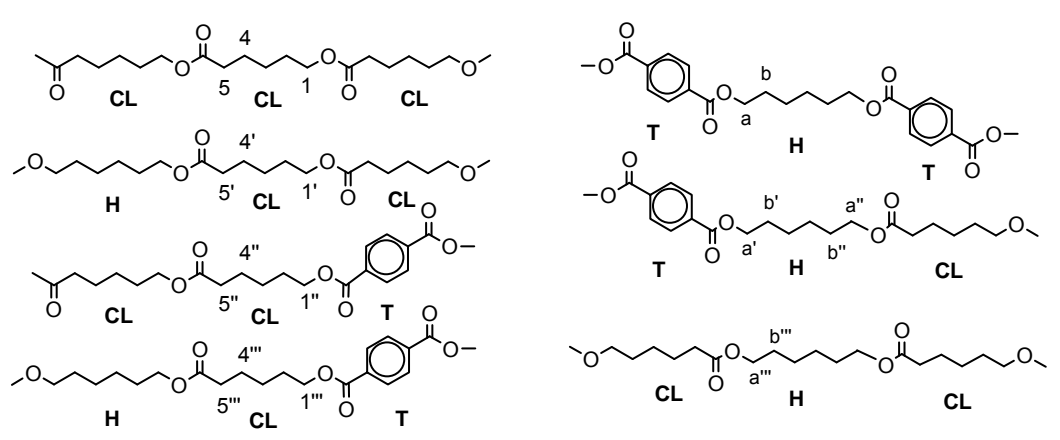

a)
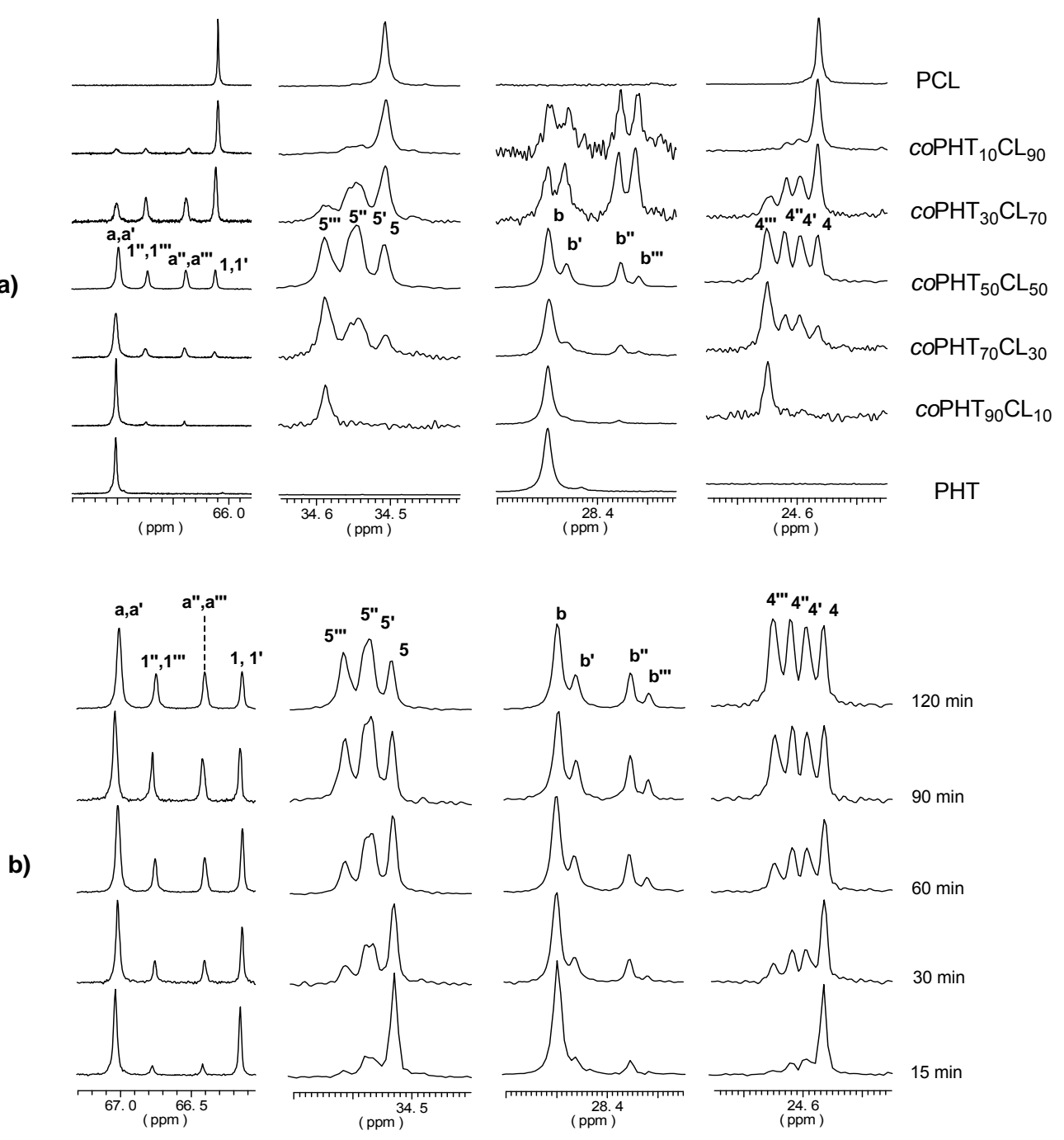

Fig. 1. a) ${ }^{13} \mathrm{C}-\mathrm{NMR}$ spectra of $\mathrm{COPHT}_{\mathrm{x}} \mathrm{CL}_{\mathrm{y}}$ and b) $\mathrm{coPHT}_{50} \mathrm{CL}_{50}$ obtained from $c(\mathrm{HT})_{6-7}$ cyclic oligomers and $\mathrm{CL}$ at different reaction times recorded in $\mathrm{CDCl}_{3 /} \mathrm{TFA}$ 9/1 with triad sequence assignment in the region of $\alpha, \beta-\mathrm{CH}_{2}$ of hexamethylene units and $\delta$ and $\varepsilon-\mathrm{CH}_{2}$ of $\mathrm{CL}$ units. 
In reference 19 , we used the region of $\alpha-\mathrm{CH}_{2}$ of both hexamethylene and $\mathrm{CL}$ units to calculate the number average sequence lengths and randomness of $\mathrm{CL}$ an HT units, but in fact other sequences were not taken into account and then the values obtained were not good enough. Now we use the region of the $\beta-\mathrm{CH}_{2}$ of hexamethylene units that split into four peaks due to the three different triads centered in $\mathrm{H}$ units. By integration of these peaks and using the equations mentioned in the text, taken from ref. 22, the randomness degree was recalculated for these copolymers.

\begin{tabular}{|c|c|c|c|c|}
\hline \multicolumn{5}{|c|}{$\begin{array}{l}\text { Table } 1 \\
\text { Compared degree of randomness of of } \mathrm{COPHT}_{x} \mathrm{CL}_{y} \text { obtained from } c(\mathrm{HT})_{6-7} \\
\text { cyclic oligomers and } \mathrm{CL} \text { taken from ref. } 19 \text { and the recalculated ones using } \\
\text { the new methodology proposed in the text [20]. }\end{array}$} \\
\hline \multirow[b]{2}{*}{ Copolyester } & \multirow[b]{2}{*}{$t(\min )$} & \multicolumn{2}{|c|}{ composition $^{\mathrm{a}}$} & \multirow{2}{*}{$\begin{array}{c}\text { Randomness } \\
(B)\end{array}$} \\
\hline & & $X_{\mathrm{HT}}$ & $x_{\mathrm{CL}}$ & \\
\hline $\mathrm{COPHT}_{90} \mathrm{CL}_{10}$ & 120 & 92.1 & 7.9 & $\begin{array}{l}1.01^{b} \\
0.83^{c}\end{array}$ \\
\hline $\mathrm{CoPHT}_{70} \mathrm{CL}_{30}$ & 120 & 73.7 & 26.3 & $\begin{array}{l}0.83^{b} \\
1.04^{c}\end{array}$ \\
\hline \multirow[t]{4}{*}{$\mathrm{CoPHT}_{50} \mathrm{CL}_{50}$} & 30 & 46.9 & 53.1 & $\begin{array}{l}0.64^{b} \\
0.74^{c}\end{array}$ \\
\hline & 60 & 45.5 & 54.4 & $\begin{array}{l}0.68^{b} \\
0.83^{c}\end{array}$ \\
\hline & 90 & 46.9 & 53.2 & $\begin{array}{l}0.76^{b} \\
0.96^{\mathrm{c}}\end{array}$ \\
\hline & 120 & 51.0 & 49.0 & $\begin{array}{l}0.84^{b} \\
0.98^{c}\end{array}$ \\
\hline $\mathrm{coPHT}_{30} \mathrm{CL}_{70}$ & 120 & 25.1 & 74.9 & $\begin{array}{l}0.82^{b} \\
0.95^{c}\end{array}$ \\
\hline $\mathrm{coPHT}_{10} \mathrm{CL}_{90}$ & 120 & 9.9 & 90.1 & $\begin{array}{l}0.46^{b} \\
0.76^{c}\end{array}$ \\
\hline
\end{tabular}

